\title{
Methodology to Create Reproducible Validation/Reference Materials for Comparison of Filter-Based Measurements of Carbonaceous Aerosols That Measure BC, BrC, EC, OC, and TC
}

\author{
Paul A. Solomon ${ }^{1, *(\mathbb{D}}$, Anna-Marie Hyatt ${ }^{2}$, Anthony D. A. Hansen ${ }^{3}$, James J. Schauer ${ }^{4}$, Nicole P. Hyslop ${ }^{5}$, \\ John G. Watson ${ }^{6}$, Prakash Doraiswamy ${ }^{7}$ iD and Paige Presler-Jur ${ }^{7}$
}

check for

updates

Citation: Solomon, P.A.; Hyatt, A.-M.; Hansen, A.D.A.; Schauer, J.J.; Hyslop, N.P.; Watson, J.G.; Doraiswamy, P.; Presler-Jur, P. Methodology to Create Reproducible Validation/Reference Materials for Comparison of Filter-Based Measurements of Carbonaceous Aerosols That Measure BC, BrC, EC, OC, and TC. Metrology 2021, 1, 142-165. https://doi.org/ $10.3390 /$ metrology1020010

Received: 2 August 2021

Accepted: 28 October 2021

Published: 26 November 2021

Publisher's Note: MDPI stays neutral with regard to jurisdictional claims in published maps and institutional affiliations.

\section{Copyright: (c) 2021 by the authors.} Licensee MDPI, Basel, Switzerland. This article is an open access article distributed under the terms and conditions of the Creative Commons Attribution (CC BY) license (https:// creativecommons.org/licenses/by/ $4.0 /)$.
Independent Consultant in Air Quality, Henderson, NV 89052, USA

2 Contractor to Magee Scientific Corporation, Las Vegas, NV 89119, USA; annamariehyatt@hotmail.com

Magee Scientific Corporation, Berkeley, CA 94704, USA; tony.hansen@mageescientific.com

4 Wisconsin State Laboratory of Hygiene, University of Wisconsin-Madison, Madison, WI 53706, USA; jjschauer@wisc.edu

Air Quality Research Center, University of California Davis, Davis, CA 95616, USA; nmhyslop@ucdavis.edu 6 Division of Atmospheric Sciences, Desert Research Institute, Reno, NV 89512, USA; John.Watson@dri.edu

RTI International, Research Triangle Park, NC 27709, USA; pdoraiswamy@rti.org (P.D.); pjur@rti.org (P.P.-J.)

* Correspondence: psolomon840@gmail.com

Abstract: A simple method that reproducibly creates validation/reference materials for comparison of methods that measure the carbonaceous content of atmospheric particulate matter deposited on filter media at concentrations relevant to atmospheric levels has been developed and evaluated. Commonly used methods to determine the major carbonaceous components of particles collected on filters include optical attenuation for "Black" (BC) and "Brown" (BrC) carbon, thermal-optical analysis (TOA) for "Elemental" (EC) and "Organic" (OC) carbon, and total combustion for "Total" carbon (TC). The new method uses a commercial inkjet printer to deposit ink containing both organic and inorganic components onto filter substrates at programmable print densities (print levels, as specified by the printer-software combination). A variety of filter media were evaluated. The optical attenuation (ATN) of the deposited sample was determined at $880 \mathrm{~nm}$ and $370 \mathrm{~nm}$. Reproducibility or precision (as standard deviation or in percent as coefficient of variation) in ATN for Teflon-coated glass-fiber, Teflon, and cellulose substrates was better than $5 \%$. Reproducibility for other substrates was better than $15 \%$. EC and OC measured on quartz-fiber filters (QFF) compared to ATN measured at $880 \mathrm{~nm}$ and $370 \mathrm{~nm}$ on either QFF or Teflon-coated glass-fiber yielded $\mathrm{R}^{2}>0.92$ and $>0.97$, respectively. Four independent laboratories participated in a round robin study together with the reference laboratory. The propagated standard deviation among the five groups across all print levels was $<2.2 \mathrm{ATN}$ at $880 \mathrm{~nm}$ and $<2.7 \mathrm{ATN}$ at $370 \mathrm{~nm}$ with a coefficient of variation of $<2 \%$ at $\sim 100 \mathrm{ATN}$.

Keywords: optical attenuation; thermal-optical analysis; transmissometer; black carbon; brown carbon; elemental carbon; organic carbon; total carbon

\section{Introduction}

Carbonaceous material is a critically important aerosol component of indoor and outdoor ambient atmospheres impacted by natural and anthropogenic sources, leading to potential significant adverse effects on human health, visibility, and climate change. Optical attenuation by carbon in a micro-crystalline graphitic form ("Black" or "Elemental" carbon, $\mathrm{BC}$ or EC) perturbs the radiation balance when freely suspended in air, reduces cloud albedo when incorporated into droplets, and accelerates thawing when deposited onto formerly reflecting snow or ice surfaces [1-8]. These optical effects led to the recognition of $\mathrm{BC}$ as the second or third most important radiative forcing agent for climate change produced by human activity $[1,2,4,6,8,9]$. High-temperature combustion of carbonaceous fuels creates pyrolyzed ultrafine particles that can enter the lungs with some portion 
crossing the lung-blood barrier and passing into cells and tissues [10]. Toxicological as well as short-term epidemiological and long-term cohort studies of average BC exposures provide sufficient evidence of an association between BC concentrations and health effects, including cardiopulmonary hospital admissions and all-cause and cardiovascular mortality [11-15]. Toxicological studies suggest that BC particles themselves may not be the toxic component of PM2.5, but they may transport adsorbed pollutants with a range of toxicity (e.g., organic species) into the lungs, that may then enter the blood circulation [11,16]. For these reasons, $\mathrm{BC}$ is recognized as one of the leading indicators of both the adverse public health and climate forcing impacts of combustion emissions. Consequently, sampling and analysis of the carbonaceous components of atmospheric aerosols is an essential research and monitoring activity.

In recent decades, researchers have evaluated different approaches to developing reference or validation methods for the measurement of $\mathrm{BC}$ and "brown" carbon (BrC) by photometric methods; as well as organic carbon (OC) and elemental carbon (EC) measured by a variety of optical and/or thermal methods. Results from an international workshop that was held to address this longstanding issue and examine a range of possible materials and methods concluded that there was an absence of reference materials for comparing instruments that measure soot (BC, OC, EC) by light absorption or thermal type methods after collection on appropriate filter media [17]. Müller et al. [18] used carbon black (Printex ${ }^{\circledR} 75$, a pigment used in inkjet printers) to compare aerosol photometers that measure light absorption. In general, they observed a large variation between the responses to absorbing aerosol particles for different types of instruments. Other groups have used Nigrosin (https: / / en.wikipedia.org/wiki/Nigrosin, accessed 2 November 2021), a water soluble, nitrogen-containing synthetic dye commonly used in microscopy as a cell (bacterial) stain. In those studies, Nigrosin was used as a test material by generating mono- or poly-disperse particles to evaluate and compare methods that measure light absorption on filters or in situ [19-22]. These methods as well as other approaches had only limited applications [17]. Some other methods to generate reference materials are complex, requiring combustion of various gases (methane in air-[23]; ethylene in $\mathrm{O}_{2}$ and $\mathrm{N}_{2}-$ [24] as well as heating and sizing ambient samples or various other materials (e.g., Nigrosin; carbon black). Aerosol generation using water dispersible carbon black has been reported [18,25]. Other methods require resuspension of particulate matter from a bulk material, such as National Institute of Standards and Technology (NIST) Standard Reference Material (SRM) 1649a, followed by collection onto filters best suited for a specific chemical analysis method [26]. Lee et al. [27] developed reference filters for EC and OC by nebulizing a solution of a carbon black hydrosol and a potassium hydrogen phthalate $\left(\mathrm{KHP}, \mathrm{C}_{6} \mathrm{H}_{4}\right)$ onto filters resulting in uniformly deposits of known mass of EC and OC. Approaches to develop validation/reference materials for the empirically derived major carbonaceous components (EC and OC) of particulate matter are also typically limited for use with either optical or thermal methods as they may not include one of the components focusing on either comparing methods for BC or methods for OC and EC as described above. Differences in the amount of EC and OC measured by various thermal or thermal-optical analysis (TOA) methods have been shown to be a consequence of the various temperature protocols (temperature steps in inert and oxidizing atmospheres), instrument design, complexity of the environmental samples, and other factors that affect the split between the OC and EC fractions, and thus differences in the reported ambient concentrations of OC and EC [28-34]. To quantify the mass of BC in air, optical methods also require comparison to thermal or TOA methods and the mass absorption coefficient determined varies based on the methods used to determine OC and EC [35,36]. Clearly, there is a lack of a simple and reproducible method that can be used as a validation/reference material for understanding the performance of instruments that measure the major carbonaceous components in atmospheric particles.

This paper describes the first use of a commercial printer to develop a simple and reproducible validation/reference material that can be used both to evaluate and compare 
methods that measure optical attenuation (ATN) at $880 \mathrm{~nm}$, used as an estimate of BC, and ATN at $370 \mathrm{~nm}$ used as an estimate of BrC, as well as EC, OC, and TC by thermal or TOA methods (patent pending, [37]). Herein, "ink" refers to a black material, such as toner deposited onto the substrate by a 'laser jet' printer, or ink or pigment deposited onto the substrate by inkjet printers.

\section{Experimental}

Various commercial laser jet and inkjet printers and filter substrates were evaluated. Ink was printed onto a variety of filter materials as used in air quality monitoring networks and research studies [38,39] as well as paper. The method is intended for photometric instruments that estimate $\mathrm{BC}$ (and $\mathrm{BrC}$ ) on filters; therefore, we measured optical attenuation $(\mathrm{ATN})$ [defined as $\mathrm{ATN}=-100 \ln \left(\mathrm{I} / \mathrm{I}_{\mathrm{O}}\right)$; [35] through the deposited sample at two wavelengths using an optical transmissometer (SootScanTM, Model OT21, Magee Scientific, Berkeley, CA, USA). This is a widely used method for estimating the BC (measurement at $880 \mathrm{~nm}$ ) and $\mathrm{BrC}$ (incremental measurement at $370 \mathrm{~nm}$ ) components of aerosol deposits on filters [40-46]. However, since the ink included both organic and inorganic carbon, we also evaluated the method for total carbon (TC). We used TOA to quantify the amounts of OC and EC deposited onto printed quartz-fiber filters ('QFF') at different print densities, and thus evaluated the possible use of these validation/reference materials for comparison of methods that measure OC, EC, and TC by different thermal and thermal-optical analytical methods. Details of the method to create reproducible validation/reference materials for the comparison of methods that measure $\mathrm{BC}, \mathrm{BrC}, \mathrm{EC}, \mathrm{OC}$, and $\mathrm{TC}$ are provided in Supplementary Materials (Section S1).

In general, our methodical stepwise process included evaluating the reproducibility of ATN measurements of deposits printed onto various types of plain paper, to find the most uniform type of paper and that use as a baseline to evaluate the variability of printing using different printers (see Section S2). A summary of measured ATN by paper type is presented in Table S1. Once the optimum paper was identified, we evaluated laser jet printers (see Section S2) using that paper type and two others to confirm that the deposited ink did indeed result in the same ATN across different paper types. Reasonable reproducibility was achieved using laser jet printers on paper (see Table S2) so we evaluated the reproducibility of using laser jet printers to print onto Teflon ${ }^{\mathrm{TM}}$-coated glass-fiber filter tape (see Section S4; Table S3). The reproducibility of printing onto this filter tape using laser jet printers did not meet our requirements for reproducibility, so we evaluated inkjet printers to print onto Teflon-coated glass-fiber filter tape (Magee Scientific, Berkeley, CA, USA) (see Section S5). We examined different software programs (Section S6) with mean and standard deviations by print level shown in Figure S1. We also examined how different operators (printing capabilities and ATN measurements) impacted measurement precision (Section S7).

Below, we describe our detailed evaluation of the chosen inkjet printer; the results from printing onto other substrates; the results of a round robin study to measure optical attenuation on separate sample sets by four independent laboratories with considerable expertise in measurements of $\mathrm{BC}$ and $\mathrm{BrC}$ by optical attenuation; and provide results from TOA used to determine the amounts of OC and EC deposited onto quartz-fiber filters (QFF) at different print densities or print levels as specified by the printer-software combination. Print levels ranged from G00 (darkest or highest density of ink deposited) to G223 (lightest or least density of ink deposited). The stability of deposited ink on filter substrates was evaluated over time, and we also determined the inorganic and major organic chemical composition of the ink used in the chosen printer.

Filter material substrates were individually taped to a sheet of paper as described in the Section S1 and passed through a printer in its normal operating mode. Reproducibility or precision was estimated based on the standard deviation (SD) of the measured mean ATN of samples at the same print level within a set (single sheet) or across multiple sets at the same print level and position on the sheet when six to nine different print levels were used within a set. Our goal was to identify a printer which would deposit ink onto 
filter tape with a standard deviation of less than 2 ATN, or the relative standard deviation (coefficient of variation, COV) of less than $5 \%$, across multiple sample sets printed from the same roll of tape.

\subsection{Printed Filter Material-Inkjet Printers}

We initially used laser jet printers (Sections S2-S4) because they were easily available. When printing onto roll filter tape (Section S4), laser jet printers had higher than desired variability (as standard deviation) in optical attenuation. Since laser jet toner includes metal oxides [47-50], which can act as combustion catalysts influencing the OC/EC split in TOA $[29,44,49,51,52]$, and because we now considered using this method to prepare comparison standards for $\mathrm{OC}$ and EC, we discontinued using laser jet printers and continued the study with inkjet printers. We examined the variability in the measured ATN using filter tape samples printed with six inkjet printers, two of which were self-identified as "photo printers". The inkjet printer specifications are given in Table S4. Filters were processed in the same manner as described (Section S1). Results of the evaluation of different inkjet printers tested are described in Section S5. Based on these results, we chose inkjet printer \#VI (see Table S5).

Initial printing on roll filter tape using inkjet printer \#VI showed a change in ATN over $24 \mathrm{~h}$. We determined this to be due to drying of the deposited ink after printing. The ink used in inkjet printers contains a large fraction of water and or water-soluble organic solvents, pigment or ink, a surfactant and or dispersant, and other components (see for example, Table S4 [47,53,54]. Therefore, all samples were allowed to dry for a minimum of $24 \mathrm{~h}$ in a shielded box to minimize deposition of dust. Repeated subsequent analyses showed that the measured optical attenuation was stable after a $24 \mathrm{~h}$ drying period.

\subsection{Other Substrates}

Optical absorption is routinely measured on a variety of filter substrates used in air quality monitoring for estimating the content of carbonaceous aerosols in air. The IMPROVE monitoring network measures light absorption on Teflon filters using the Laser Integrating Plate Method and the Hybrid Integrating Plate/Sphere [55,56]. Presler-Jur et al. [57] measured optical absorption on nearly 5500 Teflon filters collected in EPA's National Chemical Speciation Monitoring Network [39] by automating a SootScan model OT21 transmissometer into a robotic weighing system. Based on these examples, Teflon filters were also evaluated in our study as a potential substrate for use as a light absorption validation/reference material for comparison of methods that measure $\mathrm{BC}$ and $\mathrm{BrC}$ due to: (1) the importance of the national monitoring networks [39], (2) the measurement of light absorption from Teflon filters used in monitoring networks [57], (3) the recent use of Fourier-transform infrared spectroscopy (FTIR) to estimate OC and EC from Teflon filters used in the national monitoring networks [58-60], and (4) the use of samples collected on Teflon filters to monitor and better understand the role of $\mathrm{BC}$ in climate change and health $[1,2,6,8,9,11,13-15,27]$ as well as the impact of biomass burning and wildfires on ambient $\mathrm{BrC}$ and BC concentrations [40,61-65].

Three types of Teflon filters underwent a limited evaluation. These included Teflon filters with a support ring; Zefluor ${ }^{\mathrm{TM}}$ (polytetrafluoroethylene, PTFE, with a PTFE backing); and PTFE without a backing or support ring (TF-1000). These three types of Teflon filters were taped to paper and printed in the same manner as the roll filter tape (see Experimental Procedure, Section S1), then allowed to dry for at least $24 \mathrm{~h}$. Optical attenuation was obtained as described (Section S1). Zefluor filters went through the printer successfully, but when the paper tape was removed, the top of the filter separated from the bottom damaging the filter (Figure 1g), resulting in a slightly higher standard deviation and ATN range for these filters. The other two PTFE filter types had no problems with the current protocol although the deposits were visually uneven due to the hydrophobic nature of PTFE (see Figure 1). 


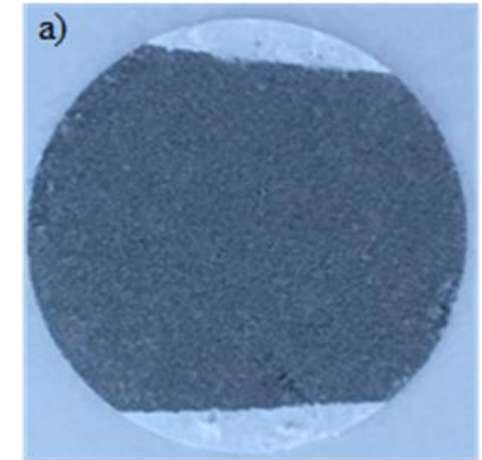

Filter Tape: G100

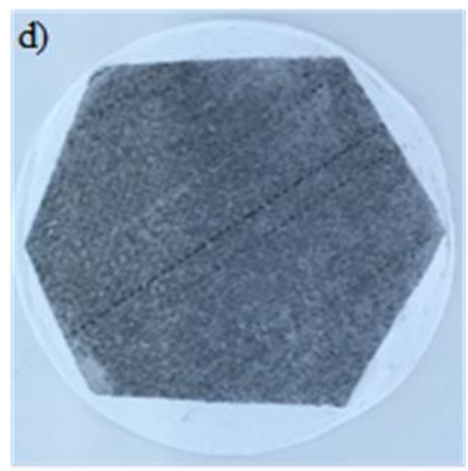

Quartz-Fiber: G70

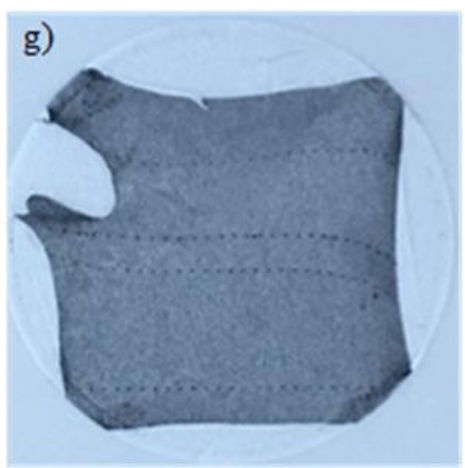

Zefluor: G70

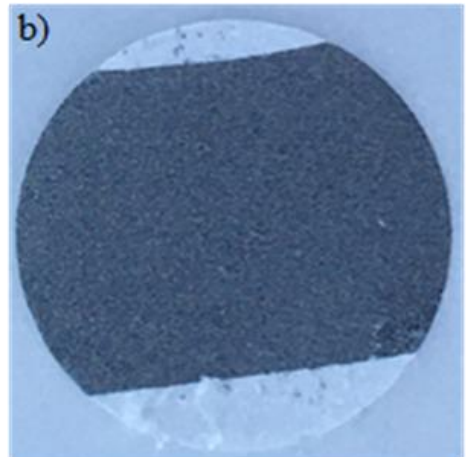

Filter Tape: G70

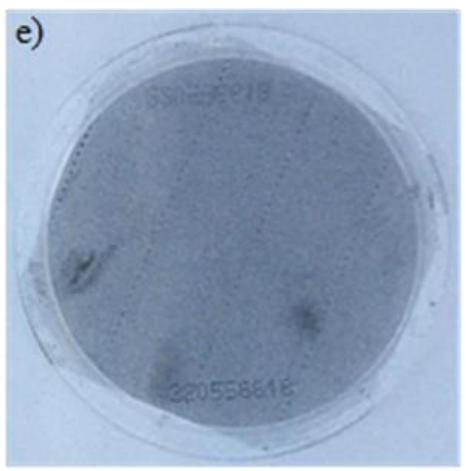

Teflon Ringed: G70

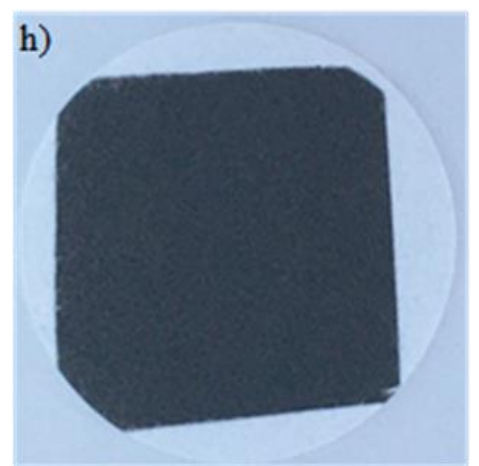

Cellulose: G70

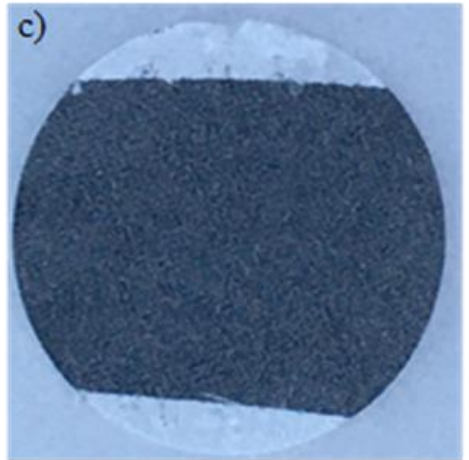

Filter Tape: G40

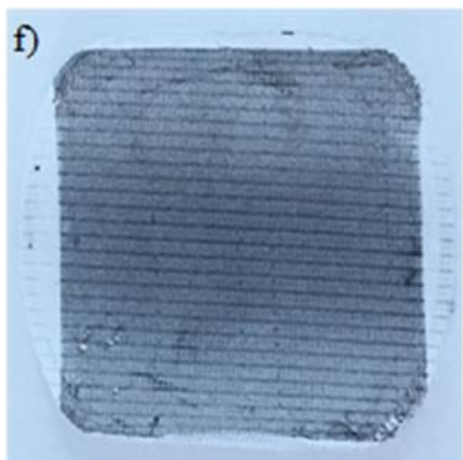

TF-1000: G70

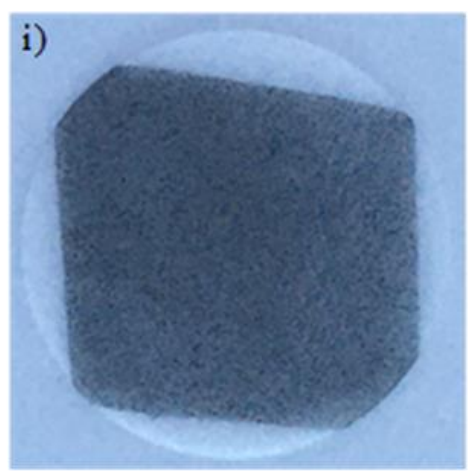

Polypropylene: G70
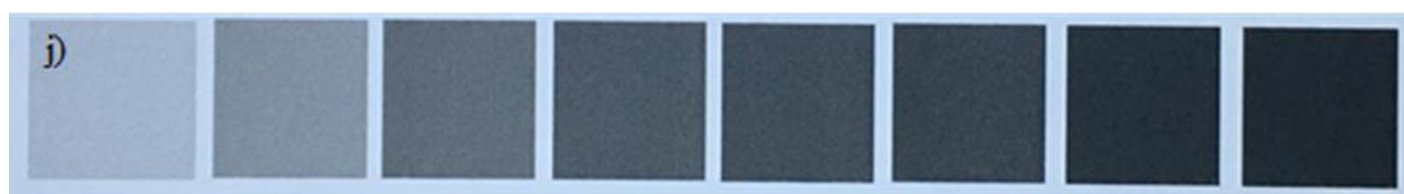

G223

G173

G127

G100

G83

G70

G40

G00

FB

Paper: Hammermill LaserPrint

Figure 1. Cont. 


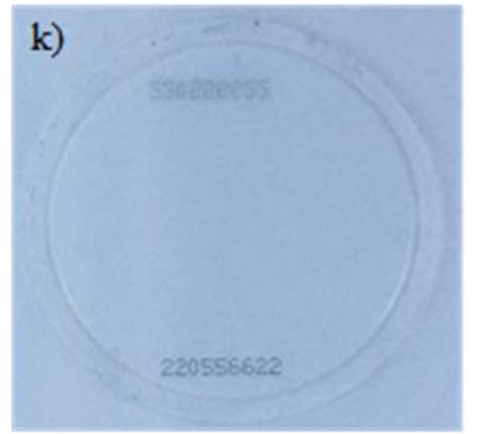

Teflon Ringed: G223

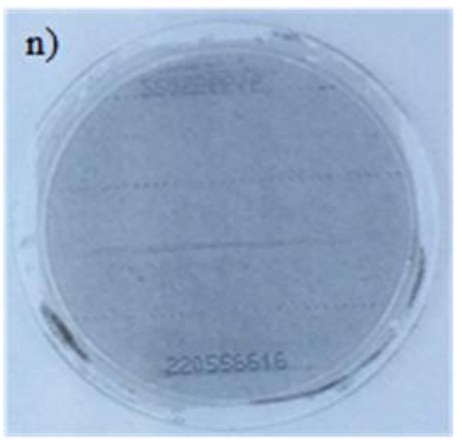

Teflon Ringed: G100

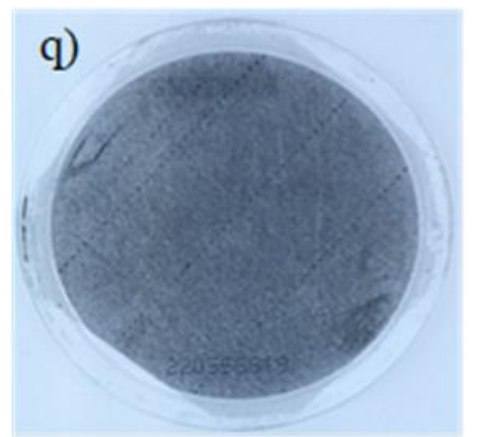

Teflon Ringed: G40

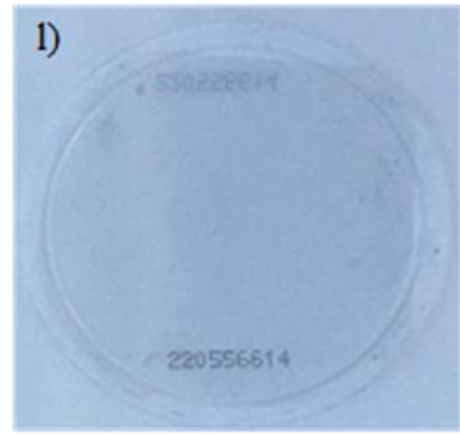

Teflon Ringed: G173

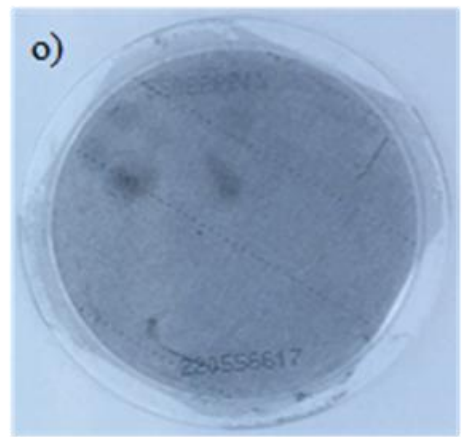

Teflon Ringed: G83

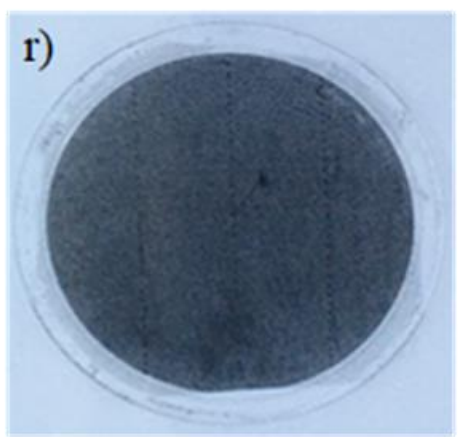

Teflon Ringed: G00

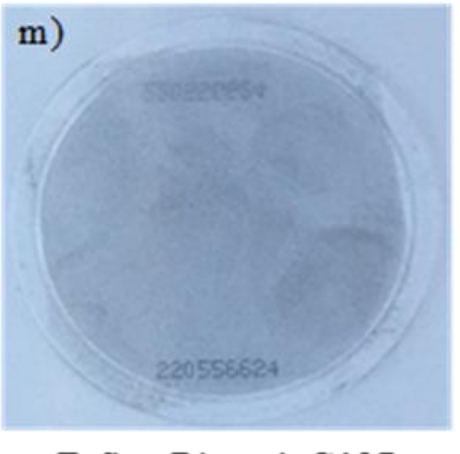

Teflon Ringed: G127

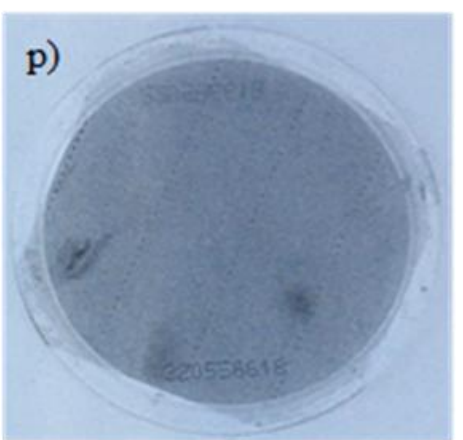

Teflon Ringed: G70

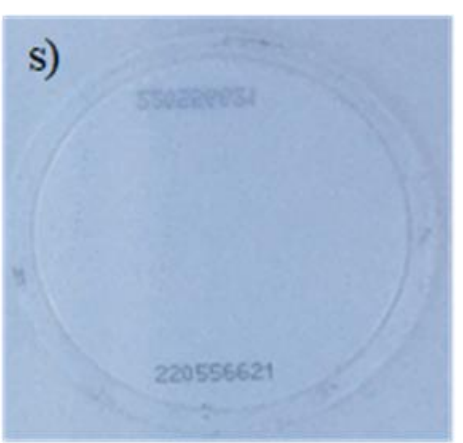

Teflon Ringed: FB

Figure 1. Deposit of inkjet ink (printer \#VI) onto different filter media illustrating the consistency of printing onto these media. (a-c) Teflon-coated glass-fiber at three print densities; (d-i) print level (density) G70: quartz-fiber, Teflon ringed, Teflon (TF1-1000), Zefluor, cellulose, polypropylene, respectively; (j) Hammermill LaserPrint premium paper: print levels (densities) G00-G223 and field blank (FB); (k-s) Teflon ringed: print levels G223-G00 and field blank. Note: as described above and in the Section S1, filters were taped onto paper for transition through the printer. White marks around the edges indicate where the tape was placed on this type of filter substrate. Damage, as seen in (g) was due to removing tape from the filter where the top and bottom of the filter separated-most were damaged much less. All filters were printed in the exact same manner, except for the print level (print density) varied.

We also printed onto a small number of polypropylene and cellulose disks to evaluate the extendibility of the method. These filter disks have also been used to collect atmospheric particulate matter in the past [66-68]. Disks of glass-fiber filter tape as used in the Model AE33 Aethalometer (part 8050, Magee Scientific, Berkeley, CA, USA) were used as the diffuser when light absorption was measured on the polypropylene substrate. No diffuser was used for the cellulose substrate due to the thickness of the substrate. The same measurement and printing protocols were used for these samples. 


\subsection{Round Robin}

Four independent external laboratories participated in a round robin study to measure the optical attenuation on three sets of samples. The participating laboratories were University of California Davis, Air Quality Research Center, Davis, CA, USA; Desert Research Institute, Division of Atmospheric Sciences, Reno, NV, USA; RTI International, Research Triangle Park, NC, USA; and the Wisconsin State Laboratory of Hygiene, University of Wisconsin-Madison, Madison, WI, USA. Each group received their own independent series of three sets, where each set consisted of filters printed at 7 print levels, a field blank, and a laboratory blank, for a total of 27 filters. Each participating laboratory was also assigned a set of optically matching polypropylene diffusers for use in the sample and reference sides of the optical transmissometer as well as a reference filter, for use in the reference position of the transmissometer. The reference filter was obtained from the same filter roll as the samples provided to each participating laboratory. Laboratories also received a standard operating procedure to specify the protocol. Optical attenuation of the blank or printed filters was not provided to participant laboratories. The reference laboratory used the diffusers and reference filter assigned to each laboratory when measuring optical attenuation associated with samples from that participating laboratory. Filters were stored in $47 \mathrm{~mm}$ plastic petri dishes, sealed in plastic bags, and shipped via standard ground transportation at ambient temperature.

For the round robin, blank values were obtained on each filter in the reference laboratory prior to shipping clean filters to each test group. Blank values were measured by participants and filters were sent back to the reference laboratory whereupon $10 \%$ of the filters were reanalyzed prior to printing at the specified print levels. Results were within the uncertainty of the instrument ( $\pm 1 \mathrm{ATN}, 0.06 \mu \mathrm{g} / \mathrm{cm}^{2} \mathrm{BC}$ on a filter). Optical attenuation was measured on filters with ink deposited at the reference laboratory and then shipped back to participants where optical attenuation was again measured on each filter following the protocol provided. Filters were then shipped back to the reference laboratory where a final measurement of optical attenuation was obtained on all samples. All participating laboratories and the reference laboratory measured all filters in triplicate as indicated by the protocol. Measuring ATN on the printed filters before and after shipping helped ensure that changes did not occur during shipping or handling.

\subsection{Quartz-Fiber Filters (QFF)}

To quantify the amount of inorganic and organic carbonaceous components of ink deposited onto the various filter substrates at a given print level, ink was deposited onto QFFs (Pall, type 2500QAT-UP; Pall Corporation, Port Washington, NY, USA) and analyzed for EC and OC content using the ACE-Asia OC/EC TOA protocol [69]. We also evaluated the relationship between ATN measured on QFF and Aethalometer filter tape to the mass $\left(\mu \mathrm{g} / \mathrm{cm}^{2}\right)$ of OC and EC determined on QFF by TOA.

The TOA protocol had been slightly modified from that described by Schauer et al., [69] by increasing the hold time at the He-only temperature steps by $20 \mathrm{~s}$. The OC/EC analysis laboratory provided clean (heat-treated) QFFs to the reference laboratory. Heat treatment reduces the blank level of OC associated with filters as received from the manufacturer. Filters were shipped in heat-treated aluminum foil that lined plastic petri dishes, sealed with Teflon tape, and sealed inside plastic bags. Shipping to and from the reference and analysis laboratory was done at ambient temperatures using overnight delivery.

A series consisting of 11 sets of filters at 7 seven print densities (print levels), each set with a field blank, were analyzed for OC, EC, and TC (here TC = OC + EC as provided by the analysis laboratory). ATN at $880 \mathrm{~nm}$ and $370 \mathrm{~nm}$ was measured before and after printing by the reference laboratory, and each sample was corrected by subtracting its respective sample and field blank ATN from the final ATN value. In addition, two QFF were used as laboratory blanks, which were not opened in the reference laboratory, and analyzed for OC and EC to obtain a baseline value for OC and EC levels. Values for each laboratory blank were $0.37 \pm 0.12 \mu \mathrm{g} / \mathrm{cm}^{2}$ and $0.29 \pm 0.11 \mu \mathrm{g} / \mathrm{cm}^{2}$ for OC and $0.00 \pm 0.05 \mu \mathrm{g} / \mathrm{cm}^{2}$ 
for both EC laboratory blanks. These filters were used to check for possible EC or OC contamination during transport to and from and within the participants' laboratories and within the reference laboratory and indicated that no contamination was observed.

Visually, the ink printed onto these QFF filters appeared to have an uneven loading (Figure 1). However, the standard deviation of the ATN measured on rotated QFF triplicates was $<2(880 \mathrm{~nm})$ on $85 \%$ and $91 \%(370 \mathrm{~nm})$ of the total sample set $(n=97)$ and only 2 samples had a standard deviation $>3$ ATN. The OT21 transmissometer measures ATN through a $15 \mathrm{~mm}$ in diameter circle in the middle of the filter, and assumes a uniform distribution across the entire filter. This is significant for OC/EC analysis since the $1 \mathrm{~cm}^{2}$ punch can be taken from any portion of the filter. To evaluate the consistency of printing across a filter and as standard quality assurance for the OC/EC analysis, we took triplicate $1 \mathrm{~cm}^{2}$ punches for EC and OC from 19 filters, including three field blanks ( $20 \%$ of the total printed filters). Quartz-fiber filters used for triplicate EC and OC analysis were chosen based on triplicate ATN measurements of the printed filters having a relatively high standard deviation (>2 ATN), suggesting filters where the ink might be less consistently deposited. It is important to note that while QFFs are not usually used to obtain measurements of optical attenuation due to the high variability of ATN measured on QFFs, we were in fact able to use them here to evaluate and quantify the relationship between ATN to carbon content when comparing ATN measured by the OT21 (15 mm in diameter circle) and OC or EC measured by TOA $\left(1 \mathrm{~cm}^{2}\right.$ punch).

Figure 2 illustrates an example of a typical thermogram from the analysis of a QFF with ink deposited using inkjet printer \#VI and Adobe ${ }^{\circledR}$ Photoshop ${ }^{\circledR}$ software. The red line on the chart showing laser transmission (used to correct for pyrolysis) is flat during the TOA analysis He-only steps, indicating that the organic components remaining in the ink after drying do not char in helium as the temperature is increased from ambient to $870{ }^{\circ} \mathrm{C}$. Due to the nature of the OC/EC method, split times were more variable for triplicate measurements as determined by the automated TOA analysis software, apparently leading to slightly more variability in the amounts of measured OC and EC mass than anticipated. However, the total carbon (sum of OC + EC) for triplicate samples was very consistent and within the error of the analysis, suggesting that the variability in EC vs. OC was due to differences in the TOA software assigned split times. To overcome this uncertainty, the split time was fixed at $480 \mathrm{~s}$ as suggested by the OC/EC analysis laboratory. Results shown in Figure S2 indicate that no practical difference was observed, depending on how the split time between OC and EC was established, with slopes and $R^{2}$ values essentially equal to 1 and small intercepts. The consistency of the total carbon result (TC = OC + EC) is also encouraging for the use of this method to create a comparison reference standard for TOA or total combustion analysis of TC in environmental samples. Additionally, the lack of pyrolysis and the general consistency between the results from fixed vs. software-assigned split times, and the linearity of the results, suggests that this method might be used to compare differences in OC and EC split times between different TOA protocols. 


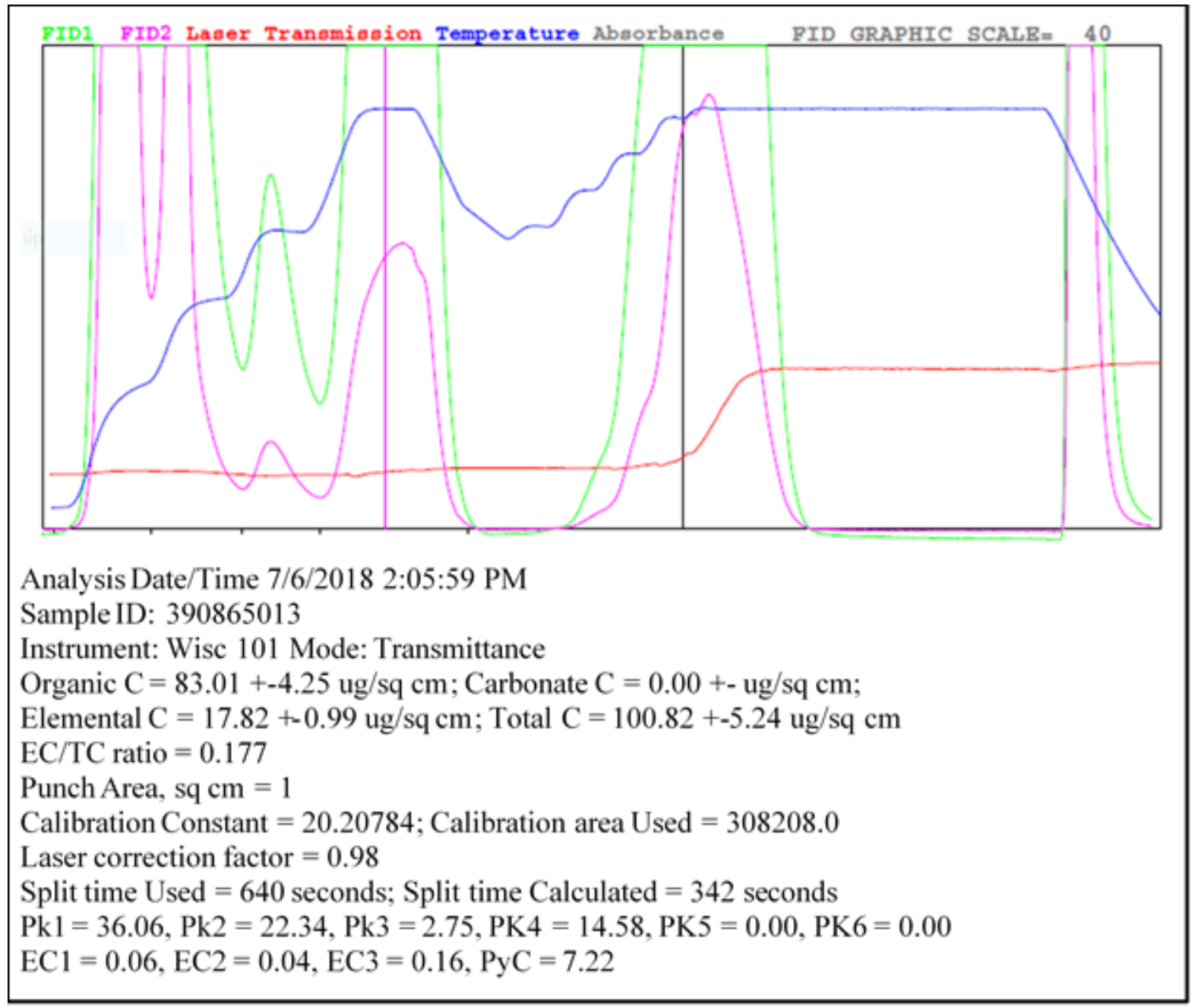

Figure 2. Thermogram of TOA of a quartz-fiber filter with ink deposited at print level G70 using inkjet printer \#VI and Adobe Photoshop software. This example is typical of all thermograms obtained when analyzing inkjet ink deposited onto QFF. Note the lack of pyrolysis carbon (flat laser transmission) during the He-steps.

\section{Results and Discussion}

\subsection{Inkjet Printers}

Results presented in Table 1 illustrate the variability [standard deviation and range (maximum ATN-minimum ATN measured per roll)] for each of four filter tape rolls measured at $880 \mathrm{~nm}$ and $370 \mathrm{~nm}$ at print levels between G223-G40. The range is important since it indicates the minimum and maximum ATN values that were observed for that filter tape roll that might be measured by an independent laboratory if used as a validation or reference material. Between 15 and 23 sets of samples were printed from each roll. The software print level is shown in Table 1 since the average ATN varied from roll-to-roll. Sample blank adjusted field blank values varied slightly by roll filter tape (Table 1) and on average ranged from approximately -0.10 to 0.18 ATN at $880 \mathrm{~nm}$ and -0.8 to 0.20 ATN at $370 \mathrm{~nm}$ across the four rolls. While these average values were typically below the uncertainty of the transmissometer, blank adjusted field blank corrections were applied since the range of field blanks was up to $3.3 \mathrm{ATN}$, although only a couple of samples were above 1 ATN. As shown in Table 1, the average blank corrected optical attenuation among the filter tape rolls differed by approximately 4.5 ATN at print level G173 (light print density) and approximately 19 ATN at print level G70 (medium print density) indicating that each filter tape roll has a slightly different structure impacting the transmission of light through the substrate. On the other hand, within a filter tape roll, at either wavelength and 
at all but the lowest density print level, blank corrected measured optical attenuation was reproducible to better than a COV of 5\%. At the lowest print density (G223), results were reproducible to within $15 \%$.

Table 1. Optical attenuation (ATN) measured by the OT21 transmissometer at $880 \mathrm{~nm}$ and $370 \mathrm{~nm}$, on each Aethalometer filter tape roll by print level. Printing was performed using inkjet printer \#VI and Adobe Photoshop software.

\begin{tabular}{|c|c|c|c|c|c|c|c|c|c|c|}
\hline \multicolumn{11}{|c|}{$880 \mathrm{~nm}$} \\
\hline & & Field Blank & G223 & G173 & G127 & G100 & G83 & G70 & $\mathrm{G} 40^{\mathrm{a}}$ & $n^{b}$ \\
\hline \multirow[t]{3}{*}{ Roll 15} & Mean & -0.10 & 6.71 & 21.37 & 46.15 & 69.38 & 88.35 & 101.09 & & 15 \\
\hline & $\mathrm{SD}^{\mathrm{c}}$ & 0.37 & 0.92 & 0.88 & 1.42 & 1.55 & 1.48 & 2.27 & & \\
\hline & Range $^{d}$ & 1.24 & 3.61 & 3.16 & 4.54 & 5.41 & 5.31 & 6.58 & & \\
\hline \multirow[t]{3}{*}{ Roll 16} & Mean & -0.07 & 5.09 & 16.72 & 35.26 & 54.09 & 69.38 & 78.20 & & 23 \\
\hline & SD & 0.39 & 0.54 & 0.70 & 0.87 & 1.43 & 1.54 & 2.22 & & \\
\hline & Range & 1.59 & 1.97 & 3.15 & 3.13 & 5.63 & 6.01 & 8.74 & & \\
\hline \multirow[t]{3}{*}{ Roll 17} & Mean & 0.18 & 5.95 & 18.82 & 39.76 & 57.22 & 74.09 & 84.38 & 130.3 & 19 \\
\hline & SD & 0.60 & 0.57 & 0.69 & 0.95 & 1.27 & 1.37 & 1.89 & 4.20 & \\
\hline & Range & 2.87 & 1.98 & 2.76 & 3.76 & 4.24 & 5.32 & 6.48 & 16.31 & \\
\hline \multirow[t]{3}{*}{ Roll 18} & Mean & -0.01 & 6.32 & 19.77 & 42.32 & 61.91 & 79.89 & 90.67 & 137.6 & 19 \\
\hline & SD & 0.70 & 0.79 & 0.68 & 1.16 & 2.23 & 2.43 & 3.39 & 4.27 & \\
\hline & Range & 2.57 & 3.14 & 2.32 & 4.66 & 9.36 & 8.74 & 11.62 & 17.51 & \\
\hline \multicolumn{11}{|c|}{$370 \mathrm{~nm}$} \\
\hline & & Field Blank & G223 & G173 & G127 & G100 & G83 & G70 & $\mathrm{G} 40^{\mathrm{a}}$ & $n^{b}$ \\
\hline \multirow[t]{3}{*}{ Roll 15} & Mean & 0.20 & 4.86 & 16.96 & 37.10 & 57.95 & 75.26 & 84.67 & & 15 \\
\hline & $\mathrm{SD}^{\mathrm{c}}$ & 0.27 & 0.54 & 0.75 & 0.79 & 1.56 & 1.64 & 2.51 & & \\
\hline & Range $^{\mathrm{d}}$ & 1.01 & 2.09 & 3.57 & 3.01 & 5.79 & 5.88 & 9.40 & & \\
\hline \multirow[t]{3}{*}{ Roll 16} & Mean & 0.20 & 4.86 & 16.96 & 37.10 & 57.95 & 75.26 & 84.67 & & 23 \\
\hline & SD & 0.27 & 0.54 & 0.75 & 0.79 & 1.56 & 1.64 & 2.51 & & \\
\hline & Range & 1.01 & 2.09 & 3.57 & 3.01 & 5.79 & 5.88 & 9.40 & & \\
\hline \multirow[t]{3}{*}{ Roll 17} & Mean & 0.09 & 5.85 & 19.33 & 42.03 & 61.78 & 81.41 & 93.0 & 144.1 & 19 \\
\hline & SD & 0.59 & 0.42 & 0.77 & 1.08 & 1.33 & 1.52 & 1.99 & 5.66 & \\
\hline & Range & 2.28 & 1.27 & 3.23 & 4.37 & 5.05 & 5.33 & 6.36 & 22.17 & \\
\hline \multirow[t]{3}{*}{ Roll 18} & Mean & -0.80 & 6.43 & 21.18 & 46.89 & 69.62 & 91.13 & 102.8 & 157.1 & 19 \\
\hline & SD & 0.91 & 0.84 & 0.83 & 1.63 & 2.71 & 3.31 & 4.14 & 4.28 & \\
\hline & Range & 3.37 & 3.38 & 3.12 & 6.39 & 10.51 & 12.70 & 13.96 & 12.85 & \\
\hline
\end{tabular}

a. Only rolls 17 and 18 included the G40 print level. ${ }^{\text {b. }}$ Number of Aethalometer roll filter samples measured at each print level, which equals number of individual samples, including the field blank per sheet: $8 \times n$ for rolls

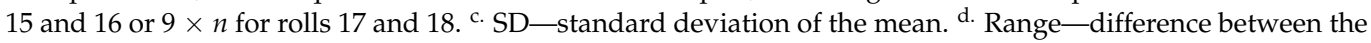
maximum and minimum ATN measured on that tape roll and at that print level.

The results presented in Table 1 indicate excellent precision when using inkjet printer \#VI, Adobe Photoshop software, and printing onto roll filter tape material. Propagated standard deviations were below 1.8 at $880 \mathrm{~nm}$ and 2.3 at $370 \mathrm{~nm}$ (Table 1) averaged across all samples in a filter tape roll and between print levels G223 and G70. The standard deviation was slightly higher at print level G40 likely due to the non-linearity of the transmissometer above 115 ATN. While the highest standard deviations were observed for print levels where the most ink was deposited onto the sample, the COV was below $3.5 \%$ at this print level. Similar results were observed at $370 \mathrm{~nm}$ (Table 1).

We examined the influence of two different ink lots using the same printer or different printers. Only a few samples were available for this evaluation since we continued to change and improve the process as the experiment progressed. Final results presented in this paper used printer \#VI-C (referred to as \#VI) unless indicated as in the analysis presented here. Specifically, we compared three sheets with ink of lot $Y$ and three sheets with ink of lot $Z$. Both used the same roll of tape and covered the print level range from G223 to G00 (lightest to darkest used). We also compared two different ink lots (X and Z) on different printers (\#VI-B, lot $\mathrm{X}$ and \#VI-C using ink lot Z), which included four sheets and two different tape rolls (two sheets each) using printer \#VI-B and four sheets using two different tape rolls (two sheets each) using printer \#VI-C. One tape roll overlapped both printers; different sheets of the same ink lot were averaged within an ink lot. This 
comparison included only the lightest three print levels (G223, G173, and G127). All comparisons were conducted at the $880 \mathrm{~nm}$ and $370 \mathrm{~nm}$ wavelengths. Results from each set of comparisons are presented in Table 2. Use of different ink lots appears to make little difference since similar results were observed when different printers and different filter tape rolls were used and compared on a relative basis used since ATN varied with print level. The largest difference (15\% relative difference) between different ink lots was observed at the lightest print level (G223, ATN 5) versus all other print levels (average approximately $5 \%$ relative difference) when the same printer and print roll were used. No difference was observed between print levels when different printers and filter tapes were used (average relative difference $\sim 4 \%$ at $880 \mathrm{~nm}$ and $\sim 7 \%$ at $370 \mathrm{~nm}$ ). This suggests that different printers and or different tape rolls influence results more than the ink lot; differences in all cases were small and less than $7 \%$ on average. Overall, these results further illustrate the potential for this method to be used as a validation/reference material for comparison of filter-based measurements of carbonaceous aerosols.

Table 2. Influence of using different ink lots with the same printer and same filter tape and different ink lots with different printers and different tape rolls.

\begin{tabular}{|c|c|c|c|c|}
\hline IR & ABS\% Rel. Diff & Slope & Intercept & $\mathbf{R}^{2}$ \\
\hline \multicolumn{5}{|l|}{ Printer \#VI-C, G123-G00, Three } \\
\hline $\begin{array}{c}\text { Sheets, Ink Lots Y and Z, Same } \\
\text { tape roll }\end{array}$ & 6.10 & 1.04 & 0.50 & 0.9999 \\
\hline $\begin{array}{l}\text { Printer \#VI-B and \#VI-C, G223, G173, } \\
\text { G127, Four Sheets, Ink Lots X and Z, } \\
\text { Three Rolls as described in the text }\end{array}$ & 4.40 & 1.03 & 0.23 & 0.9999 \\
\hline UV & ABS\% Rel. Diff & Slope & Intercept & $\mathbf{R}^{2}$ \\
\hline \multicolumn{5}{|l|}{ Printer \#VI-C, G123-G00, Three } \\
\hline $\begin{array}{c}\text { Sheets, Ink Lots Y and Z, Same } \\
\text { tape roll }\end{array}$ & 6.40 & 1.05 & 0.70 & 0.9999 \\
\hline $\begin{array}{l}\text { Printer \#VI-B and \#VI-C, G223, G173, } \\
\text { G127, Four Sheet, Ink Lots X and Z, } \\
\text { Three Rolls as described in the text }\end{array}$ & 7.10 & 1.06 & 0.27 & 0.9998 \\
\hline
\end{tabular}

3.2. Quantifying Carbonaceous Content of Ink Deposited onto Filters as Mass $\left(\mu \mathrm{g} / \mathrm{cm}^{2}\right)$ of Inorganic (EC) and Organic (OC) Carbon

The amount of ink deposited at each print level using inkjet printer \#VI was quantified as EC and OC by printing onto QFF and analyzing the samples by TOA (69). The average $\mathrm{EC}, \mathrm{OC}$, and TC mass $\left(\mu \mathrm{g} / \mathrm{cm}^{2}\right)$ at each print level is shown in Figure 3 along with results of the linear regression analysis. Results are shown for the full possible range of print densities from the lightest print level (G223, ATN 5.6 at $880 \mathrm{~nm}$ ) to the darkest print level possible by the printer-software combination (single printing) (G00, ATN 230 at $880 \mathrm{~nm}$ ). Optical attenuation at $370 \mathrm{~nm}$ was slightly higher (5.9 and $152 \mathrm{ATN}$, respectively). Error bars are one standard deviation of the 11 samples analyzed at each print level. Print level was used as the identifying metric since ATN varied by filter tape roll (Table 1), but was consistent across a filter tape roll after blank correction at either wavelength, i.e., within-roll precision was less than 3\% except at G223 (lightest print density) where it was less than $12 \%$. The EC and OC content (in $\mu \mathrm{g} / \mathrm{cm}^{2}$ ) measured on the QFFs, using software print levels G223-G70, is highly linear with a coefficient of determination $\left(R^{2}\right)$ of 0.988 for EC and 0.987 for OC. The relationship becomes slightly less linear when including print levels G40 and G00, the two darkest print densities. When G40 is included, $R^{2}$ is reduced slightly to 0.930 and 0.980 (EC and OC, respectively) and slightly further reduced when G00 is included (0.863 and 0.831 , respectively, Figure 3 ). These results suggest that when using the ink associated with inkjet printer \#VI, the print density at G70 or slightly above, might be the linear limit ( 115 ATN) of the method. At the G40 print level, the optical attenuation through the filter was 133 ATN and 151 ATN (880 nm and $370 \mathrm{~nm}$, respectively); the 
optical attenuation at G00 is approximately 230 ATN and 244 ATN $(870 \mathrm{~nm}$ and $370 \mathrm{~nm}$, respectively). Total carbon results are similar with $\mathrm{R}^{2}$ of 0.989 (Figure 3), 0.942 (G223-G40), and 0.847 (G223-G70) (G223-G00).

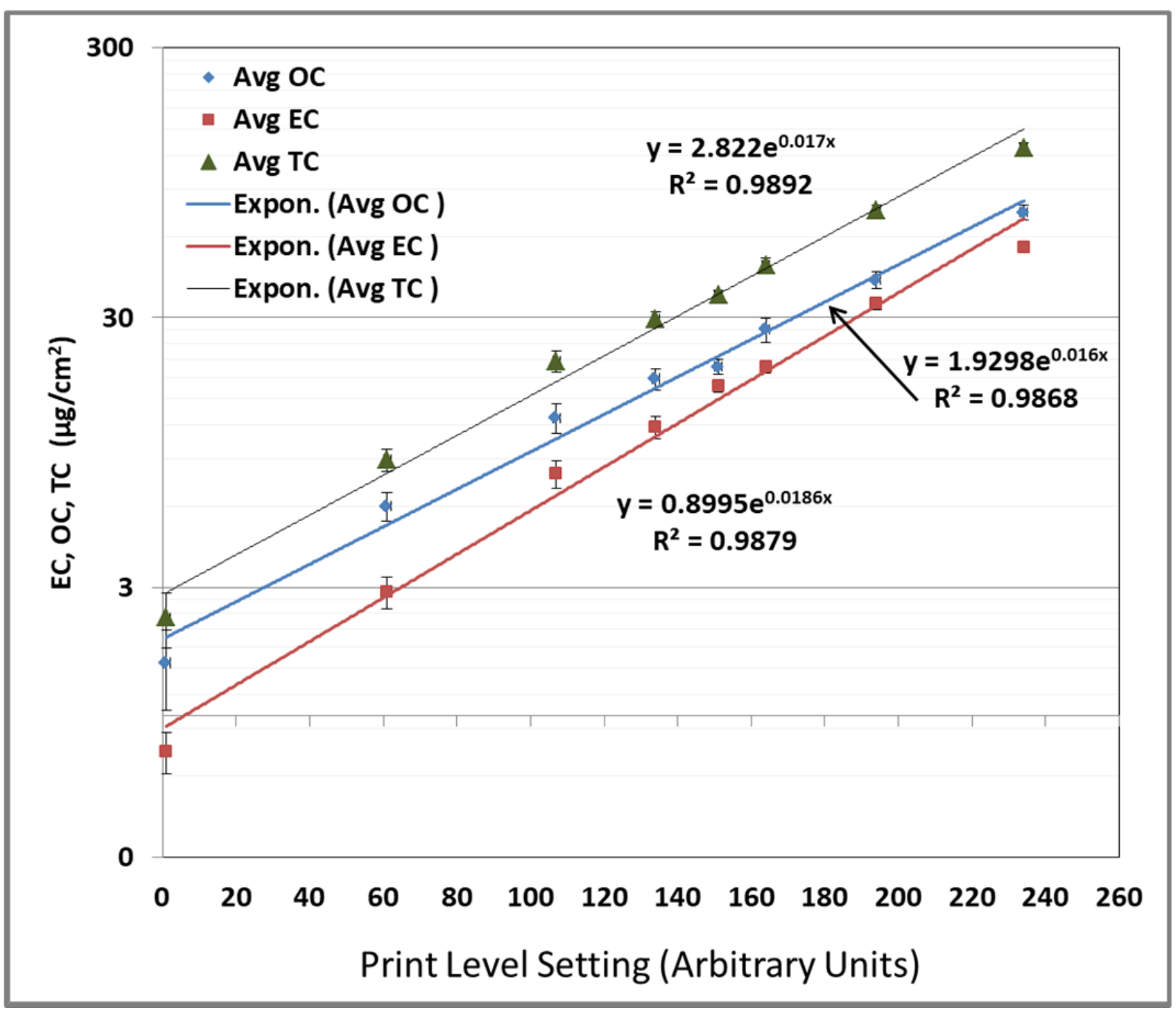

Figure 3. Ink deposited onto QFF filters at specified print levels onto Aethalometer filters and other substrates to quantify the carbon black as EC and total organic carbon as OC i. Print levels are arbitrary units as defined by the software program and described in the text. Ink was printed onto the QFF filters using inkjet printer \#VI and Photoshop software. EC and OC analysis was performed by the ACE-Asia protocol [69]. TC is the arithmetic sum of EC and OC. Error bars are 1 standard deviation of the mean. The $y$-axis is in log scale.

Four filters had 6 random replicate $1 \mathrm{~cm}^{2}$ punches analyzed by TOA to obtain a more thorough estimate of variability of printing across QFF and, thus, other substrates. The mean loading was $21.1 \pm 3.1 \mu \mathrm{g} / \mathrm{cm}^{2}$ for EC and $53.5 \pm 4.7 \mu \mathrm{g} / \mathrm{cm}^{2}$ for OC. The standard deviation of the analysis of the six punches from each of the four filters ranged from 1.3 to $3.2 \mu \mathrm{g} / \mathrm{cm}^{2}$ for EC and from 1.6 to $2.8 \mu \mathrm{g} / \mathrm{cm}^{2}$ for OC. In general, the relative standard deviation was less than $10 \%$. These results indicate that while the filter deposits onto QFF may appear uneven to the human eye (Figure 1), the ink deposits are actually fairly uniform at the analytical scale.

An example of the relationship between ATN measured on one of the Aethalometer tape rolls (\#16) and EC or OC mass loading $\left(\mu \mathrm{g} / \mathrm{cm}^{2}\right.$ ) as measured on QFF ( $n=11$ sets) is shown in Figure 4 and Figure S3, respectively. The association is a highly linear for each of the four filter tape rolls (15-18) tested versus TOA, with coefficients of determination $\left(\mathrm{R}^{2}\right)$ greater than 0.991 for EC and approximately 0.968 for OC. In these figures, reproducibility 
is expressed as 1 standard deviation of the average at each print level (G223-G70) for both ATN and for EC or OC mass loadings. For optical attenuation, as seen in the figures and as noted above, excellent precision was observed within a filter tape roll. The variability, as standard deviation, of EC and OC across the 11 filters at the same print level ranged from 0.26 to $2.2 \mu \mathrm{g} / \mathrm{cm}^{2}$ for EC and 1.0 to $5.6 \mu \mathrm{g} / \mathrm{cm}^{2}$ for OC. The relative standard deviation for EC and OC was less than 5\%, except at the lowest print level (<14\% at G223).

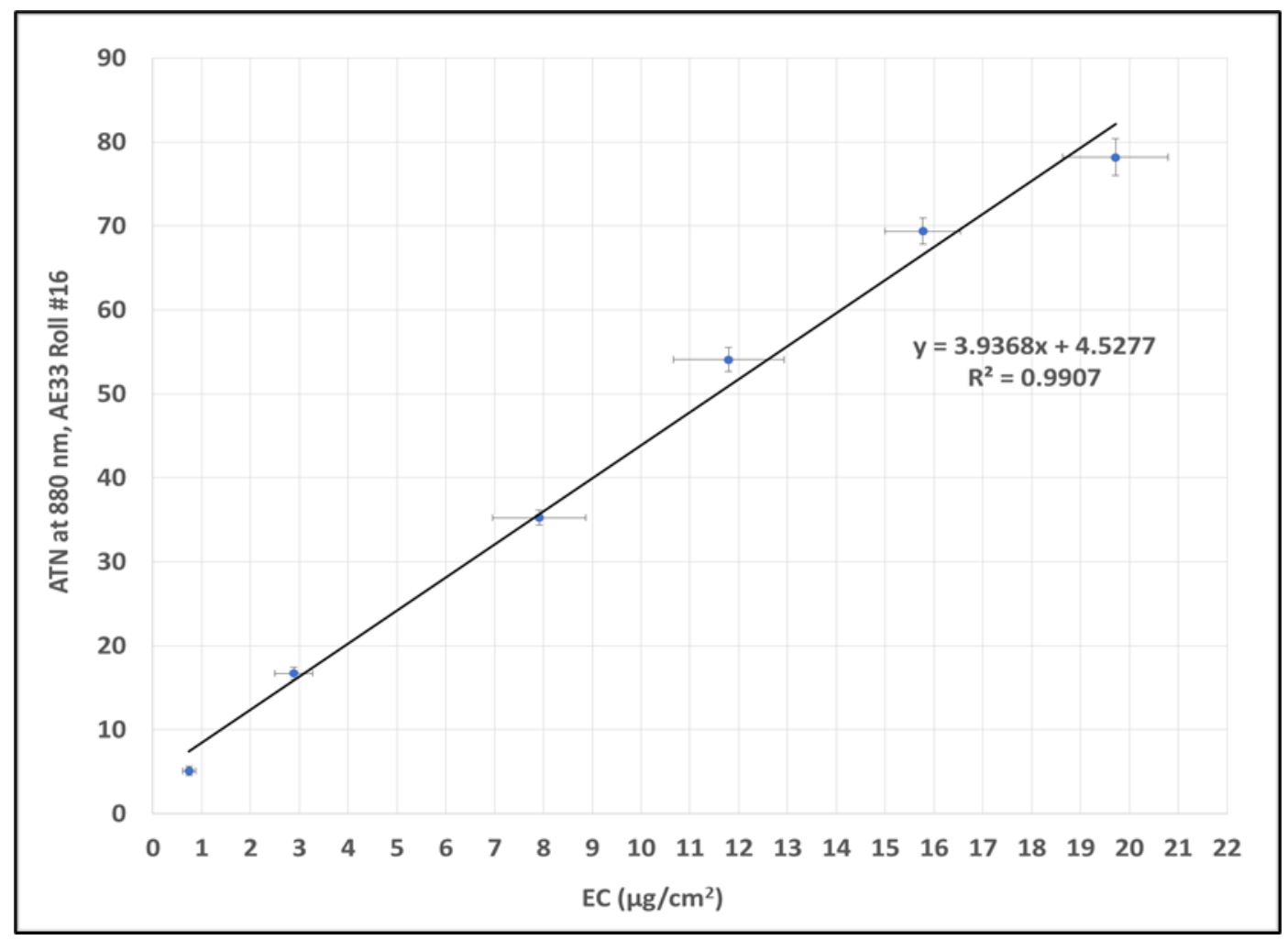

Figure 4. Comparison of optical attenuation measured on Aethalometer tape roll \#16 and EC mass loading $\left(\mu \mathrm{g} / \mathrm{cm}^{2}\right)$ measured on QFF ( $n=11$ sets). Error bars are \pm 1 standard deviation of either the ATN across all sets for roll 16 at each print level (G123-G70) (y-axis) or EC mass loading ( $x$-axis) measured at each print level. Results for OC are presented in Figure S3.

A linear relationship $\left(\mathrm{R}^{2}=0.958\right)$ also was observed between ATN measured on QFFs $\left(x\right.$-axis) and EC mass loading $\left(\mu \mathrm{g} / \mathrm{cm}^{2}\right)(y$-axis) $(n=11)$ (Figure $5 \mathrm{a})$. Similar results were observed for OC $\left(R^{2}=0.918\right)$ (Figure $\left.5 b\right)$ and TC $\left(R^{2}=0.893\right.$ at $880 \mathrm{~nm}$ and 0.956 at $\left.370 \mathrm{~nm}\right)$ (Figure S4). Each sample set included print levels G223 (lightest print density) to G00 (darkest print density). The precision of triplicate measurements as relative standard deviation of ATN for EC, OC, and TC mass loadings $\left(\mu \mathrm{g} / \mathrm{cm}^{2}\right)$ are also plotted in these figures. At $880 \mathrm{~nm}$ and $370 \mathrm{~nm}$, the precision, based on the standard deviation of triplicate ATN measurements of the QFFs with ink deposited, is better than approximately $10 \%$ at all optical attenuations measured. Precision, also based on the standard deviation of triplicate EC and OC mass measurements on the QFFs, is better than approximately $10 \%$ for samples with optical attenuation greater than 40 ATN for EC (mass loading of approximately $5 \mu \mathrm{g} \mathrm{EC} / \mathrm{cm}^{2}$ ) and $25 \mathrm{ATN}$ for OC. 


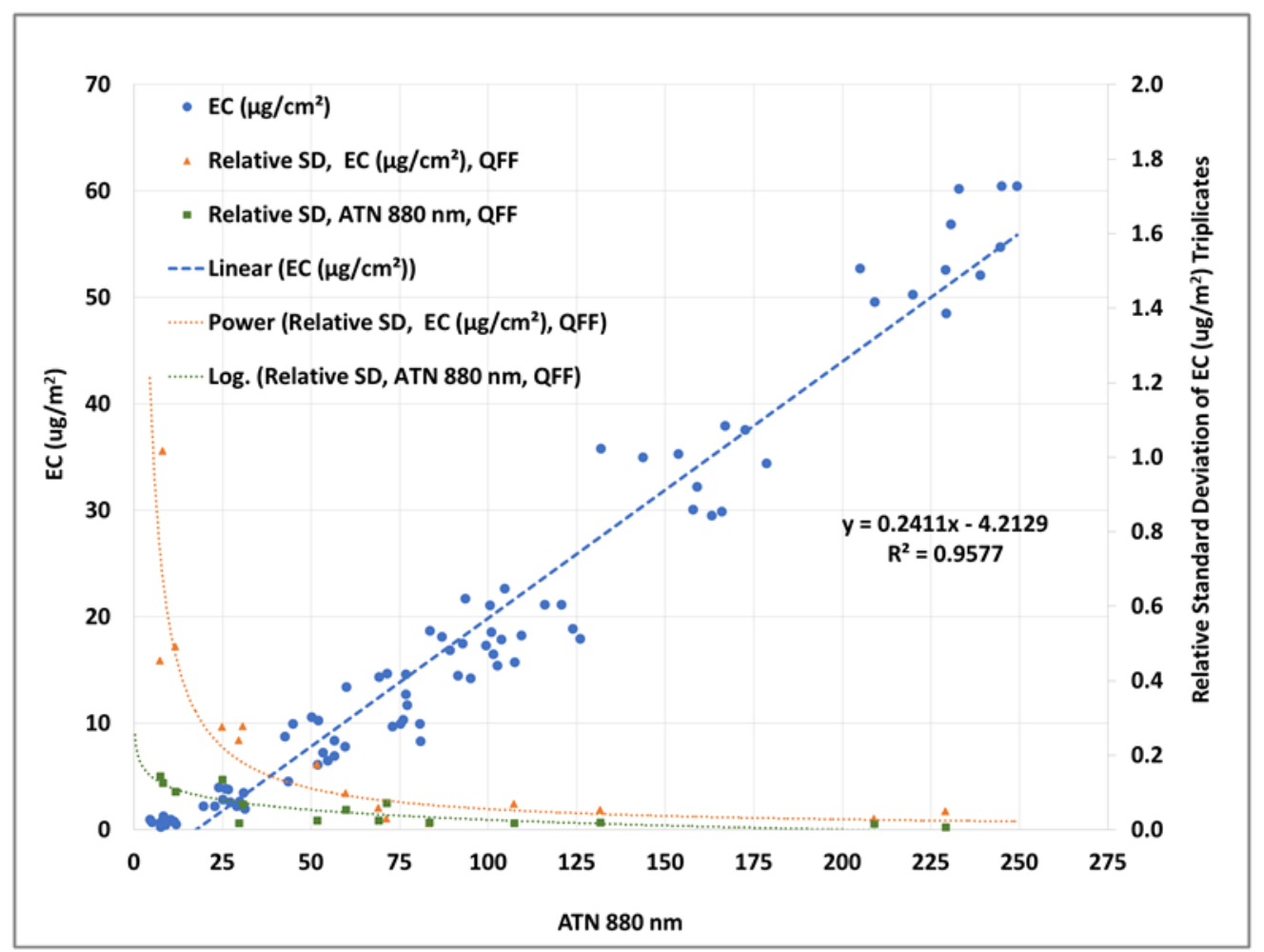

a)

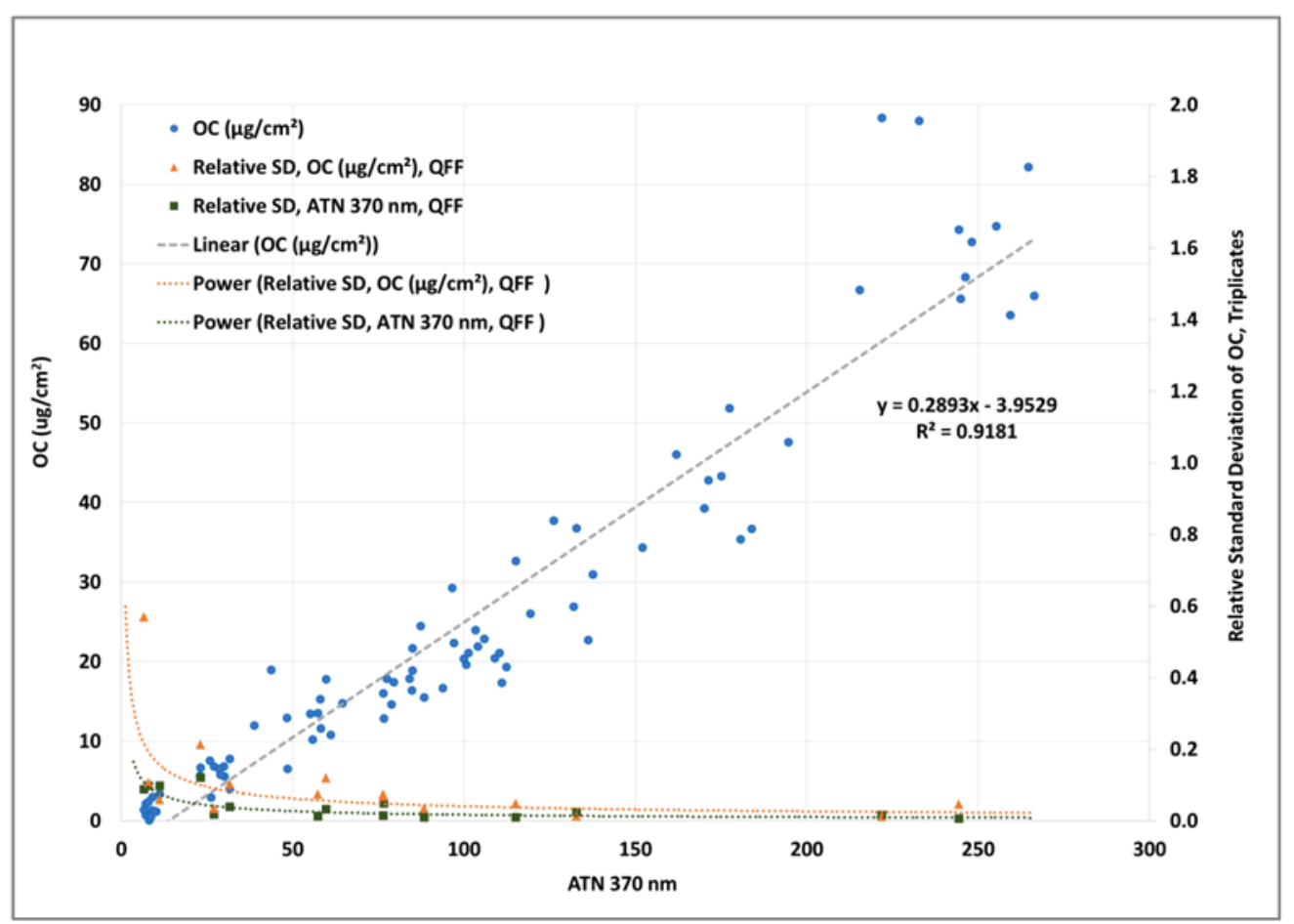

Figure 5. Comparison of ATN measured on the same QFF filters at (a) $880 \mathrm{~nm}$ to EC and (b) $370 \mathrm{~nm}$ to OC measured by TOA as a validation/reference material for comparison of filter-based methods that measure BC at $880 \mathrm{~nm}$ or $\mathrm{BrC}$ at $370 \mathrm{~nm}$. Ink was printed onto QFF filters using inkjet printer \#VI and Photoshop software. EC and OC analysis was performed by the ACE-Asia protocol [69]. Error in measurements is less than (lower ATN values) or approximately equal to the size of the data point (higher ATN values). Total carbon results are presented in Figure S4.

Comparison of EC and OC loadings to optical attenuation measured on both Aethalometer tape and QFF substrates clearly indicates that this simple method can provide excellent reproducibility for the measurement of optical attenuation, even on QFF, and may be 
a practical approach as a validation/reference material for comparison of methods that measure EC, OC, and TC by TOA, or TC by total combustion analysis.

\subsection{Other Substrates}

To evaluate the versatility of the method, ink was deposited onto different substrates that included (1) three types of Teflon (PTFE), (2) cellulose, and (3) polypropylene materials, in addition to quartz-fiber and PTFE-coated glass-fiber filters. The footnotes in Table 3 provide additional information about these substrates. Seven print levels (G223 to G40) and a field blank were included with each set and optical attenuation was measured at 880 and $370 \mathrm{~nm}$ for each sample as described previously. The mean ATN, standard deviation, and range of the optical attenuation measured on each substrate at print level G70 at both $880 \mathrm{~nm}$ and $370 \mathrm{~nm}$ is given in Table 3. The mean ATN and standard deviation for all substrates by print level are given in Figure S5a,b at $880 \mathrm{~nm}$ and $370 \mathrm{~nm}$, respectively. Data are tabulated according to print level since the measurement of optical attenuation through a filter containing ink depends on the nature of the substrate. Despite the visually uneven appearance of the ink deposited onto Teflon filters (Figure 1), ATN measured on the printed Teflon filter with ring support showed excellent reproducibility ( $\mathrm{SD}<0.55)$, a COV of less than $1.2 \%$ of the mean, and an ATN range of 1.0 (2.5\% of mean) (Table 3 ). This implies that the ink deposits are actually fairly uniform when measured at the macro-scale of $15 \mathrm{~mm}$ in diameter, which is appropriate for these methods. The variability of field blanks values also was very low $(<0.15$ at $880 \mathrm{~nm}$ and $<0.5$ at $370 \mathrm{~nm})$ for all Teflon type substrates (Table 3). Similar results were observed at $370 \mathrm{~nm}$. Reproducibility was not as good for Zefluor and TF-1000, likely due to the mechanical difficulties in handling these materials. These results indicate that the "ringed Teflon filter" as used in the US EPA's National Monitoring Network and IMPROVE programs can be printed on and used as a possible validation/reference material for comparison of methods that measure optical attenuation at both $880 \mathrm{~nm}$ and $370 \mathrm{~nm}$ using these filter materials.

Polypropylene and cellulose were also evaluated as substrates. The results are shown in Table 3 and were similar to those for the ringed Teflon filters. The measured ATN for cellulose, at $880 \mathrm{~nm}$ and the same print level, was twice as high as polypropylene (65 ATN vs. $122 \mathrm{ATN} ; n=2$ ) indicating the difference in the optical structure of the filters. Similar results were observed at $370 \mathrm{~nm}$. Optical attenuation through printed cellulose at either wavelength was highly reproducible (SD $<1 \%$ of the mean ATN); polypropylene less reproducible (SD $<9 \%$ of the mean $\mathrm{ATN}$ ). Ink deposited onto cellulose appears to have uniform coverage with excellent results for reproducibility and range (two samples), both less than $1 \%$ relative to the mean ATN and at either wavelength. Polypropylene appears to have nonuniform coverage (Figure 1), yet reproducibility and range are both less than $7 \%$ relative to the mean ATN at $880 \mathrm{~nm}$ and less than $12 \%$ at $370 \mathrm{~nm}$. Again, the ink deposits are actually fairly uniform when measured at the macro-scale. Although ATN was only measured on two sets of samples for each filter substrate, these results suggest the method provides reproducible results when using different substrate materials. QFFs had the highest variability $(n=11)$ among all the substrates tested but still better than $15 \%$ (SD/average ATN) (Table 3). These results show the flexibility of this simple and reproducible method. 
Table 3. Variability of optical attenuation (ATN) measured at $880 \mathrm{~nm}$ and $370 \mathrm{~nm}$ on various substrates using inkjet printer \#VI and Adobe Photoshop. Results are presented for print level G70. Mean and standard deviation are presented in Figure S5a and Figure S5b for all print levels (G223-G40).

\begin{tabular}{|c|c|c|c|c|c|}
\hline Substrate & Mean & $\mathrm{SD}^{\mathrm{a}}$ & Range & $n^{\mathrm{b}}$ & $\begin{array}{c}\text { Blank, } \\
\text { Mean } \pm \text { SD (Range) }\end{array}$ \\
\hline \multicolumn{6}{|c|}{$-880 \mathrm{~nm}-$} \\
\hline $\mathrm{AE} 3^{\mathrm{c}}\left(\right.$ Roll 16 $\left.{ }^{\mathrm{d}}\right)$ & 101.1 & 2.27 & 6.58 & 23 & $-0.07 \pm 0.39(1.59)$ \\
\hline $\mathrm{QFF}^{\mathrm{e}}$ & 110.3 & 10.9 & 32.5 & 11 & $2.15 \pm 2.42(8.79)$ \\
\hline PTFE with support ring ${ }^{f}$ & 38.4 & 0.43 & 1.02 & 4 & $-0.14 \pm 1.05(2.43)$ \\
\hline Zefluor $\mathrm{g}$ & 43.9 & 5.71 & 13.4 & 4 & $-0.02 \pm 0.19(0.46)$ \\
\hline Teflon (TF-1000) ${ }^{\mathrm{h}}$ & 51.5 & 4.84 & 10.2 & 4 & $0.10 \pm 0.13(0.30)$ \\
\hline Polypropylene ${ }^{\mathrm{i}}$ & 64.8 & 3.16 & 4.46 & 2 & $0.16 \pm 0.27(0.38)$ \\
\hline Cellulose $^{\mathrm{j}}$ & 121.8 & 0.48 & 0.68 & 2 & $0.70 \pm 0.31(0.44)$ \\
\hline \multicolumn{6}{|c|}{$-370 \mathrm{~nm}-$} \\
\hline AE33 ${ }^{c}\left(\right.$ Roll 16 $\left.{ }^{d}\right)$ & 84.7 & 2.51 & 9.40 & 23 & $0.20 \pm 0.27(1.01)$ \\
\hline $\mathrm{QFF}^{\mathrm{e}}$ & 118.3 & 14.4 & 40.9 & 10 & $4.34 \pm 2.76(8.87)$ \\
\hline PTFE with support ring ${ }^{f}$ & 38.4 & 0.54 & 1.22 & 4 & $-0.44 \pm 1.06(2.49)$ \\
\hline Zefluor $\mathrm{g}$ & 45.2 & 6.13 & 14.4 & 4 & $0.52 \pm 0.56(1.20)$ \\
\hline Teflon (TF-1000) ${ }^{\mathrm{h}}$ & 55.7 & 6.01 & 12.9 & 4 & $0.46 \pm 1.38(3.05)$ \\
\hline Polypropylene $^{\mathrm{i}}$ & 71.3 & 6.02 & 8.51 & 2 & $0.22 \pm 0.04(0.06)$ \\
\hline Cellulose ${ }^{j}$ & 147.9 & 1.22 & 1.72 & 2 & $0.60 \pm 0.49(0.69)$ \\
\hline
\end{tabular}

a.Precision as standard deviation of the mean. ${ }^{\text {b. }} n=$ number of samples. ${ }^{\text {c. }}$ Aethalometer tape, part No. 8050, $3.0 \mathrm{~cm} \times 1000 \mathrm{~cm}$, Magee Scientific Corporation, Berkeley, CA. ${ }^{\text {d. }}$ Roll 16 is given as an example. Table 1 provides data for other Aethalometer tape rolls used in this analysis. ${ }^{\text {e. }}$ Quartz-fiber filters, part No. 2500 QAT-UP, Pall ${ }^{\circledR}$

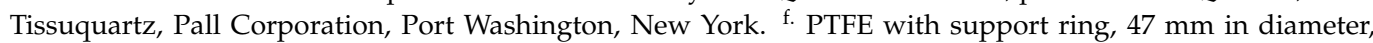
$2 \mu \mathrm{m}$ pore size, part No. PT47AN, Measurement Technology Laboratory, Minneapolis, MN. g. Zefluor, PTFE with PTFE backing, $37 \mathrm{~mm}$ in diameter, $2 \mu \mathrm{m}$ pore size, part No. P5PJ037, Pall Corporation, Port Washington, New York. Limited data for Zefluor, since the backing pulled away from the top Teflon sheet when the tape was

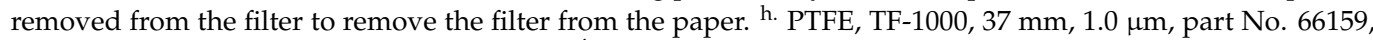
Pall Corporation, Port Washington, New York. ${ }^{i}$. Polypropylene, $25 \mathrm{~mm}$ in diameter, part No. 225-2901, SKC Inc., Eighty-Four, PA; used as a diffuser in the OT21. j. Cellulose, $47 \mathrm{~mm}$ in diameter, part no. 225-2903, SKC Inc., Eighty-Four, PA.

\subsection{Round Robin}

Optical attenuation at $880 \mathrm{~nm}$ and $370 \mathrm{~nm}$, measured by each participating laboratory and the reference laboratory in the round robin study, is presented in Figure $6 \mathrm{a}, \mathrm{b}$. Optical attenuation ranged from approximately 6 to $140 \mathrm{ATN}$ at $880 \mathrm{~nm}$ and from approximately 6 to $160 \mathrm{ATN}$ at $370 \mathrm{~nm}$. Variability among the 5 groups, presented as standard deviation, is less than $2.1 \mathrm{ATN}$ and $2.7 \mathrm{ATN}$ at $880 \mathrm{~nm}$ and $370 \mathrm{~nm}$, respectively. On a relative basis $(\mathrm{SD} /$ mean), the variability at the darkest print level was approximately $1.5 \%$ and at the lightest print level was less than $9 \%$. Figure $6 \mathrm{a}, \mathrm{b}$ also shows the range of the average attenuation measured among each of the 5 groups at each print level. The full range is given since the individual values for all filters measured at a given print level vary slightly more than the standard deviation of the average, providing the maximum variation that might be expected when comparing two or more instruments or methods. Nonetheless, the range varies from approximately 1 to 4.7 ATN at $880 \mathrm{~nm}$ and from 1.5 to 5.5 ATN at $370 \mathrm{~nm}$, from the lightest (ATN $\sim 6$ at both wavelengths) to the darkest (ATN $\sim 140$ or 160) print levels or approximately from $25 \%$ to $3 \%$, respectively. These results indicate the excellent agreement among the five groups and the reproducibility of this simple method for validating and providing a reference material for filter-based absorption measurements. 

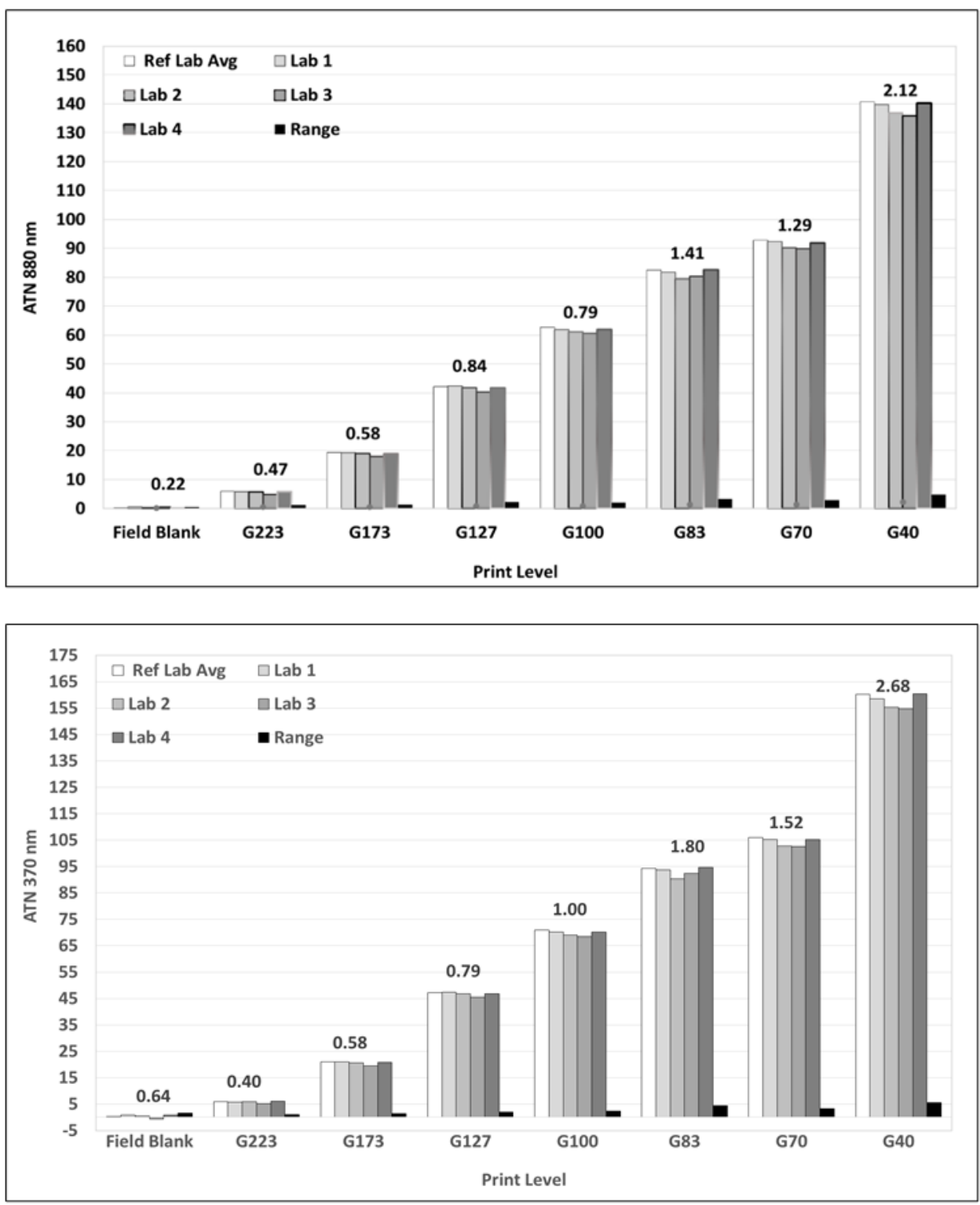

b)

Figure 6. Comparison of mean optical attenuation measured by the reference laboratory and each group participating in the round robin. Results are for AE33 Aethalometer roll filter tape samples with ink deposited at seven print levels and a field blank. A laboratory blank was also included and measured only by the reference laboratory to evaluate the possibility of contamination during shipping and while in individual laboratories. All printed filters were adjusted for the sample blank (clean filter before printing) and the field blank (after passing through the printer but ink was not intentionally deposited onto it; the field blank was associated with that specific set of seven printed filters). The field blanks were sample blank corrected. The reference laboratory average is the average of the four separate and independent filter sets sent to the participating groups and measured prior to shipping. Range (rightmost [black] bar at each print level) is the difference between the average maximum and minimum values measured among the five groups, including the reference laboratory average. Values above the bars represent one standard deviation at each print level for the four participating laboratories and the average of the four sets of measurements by the reference laboratory. (a) analysis at $880 \mathrm{~nm}$; (b) analysis at $370 \mathrm{~nm}$.

\subsection{Quality Assurance for Round Robin}

As described above, optical absorption was measured by the reference laboratory on blank and printed filters before and after measurements by the participating laboratories to help ensure the quality of the data and evaluate possible sample contamination during 
shipping or while in the participants' or reference laboratories. Three scenarios can be considered when looking at possible variations in optical attenuation when samples are sent from and received back by the reference laboratory. (1) Optical attenuation on printed roll filter tape is measured only by the reference laboratory before and after the participant's ATN measurements. (2) Optical attenuation on printed roll filter tape is measured by the reference laboratory prior to shipping to the participants and is then compared to ATN measured by the participants. (3) Optical attenuation on printed roll filter tape is measured by the reference laboratory after the participant groups' measurements and is compared to ATN measured by the participants. The average difference in optical absorption for all three scenarios ranges from approximately 1.2 ATN to approximately 1.7 ATN at $880 \mathrm{~nm}$ and $370 \mathrm{~nm}$, respectively, indicating that the samples were not altered due to shipping or being handled in the participants' or reference laboratories. Field blanks were low $(<0.7 \mathrm{ATN}$ at $880 \mathrm{~nm} ;<1.4 \mathrm{ATN}$ at $370 \mathrm{~nm})$ indicating minimal to no contamination due to printing, shipping, or during analysis. Results are summarized in Table S6.

\subsection{Long-Term Storage Study}

Re-analysis of samples was typically performed after relatively short periods of storage, approximately a month or less to evaluate the short-term stability of the filters and as part of our quality assurance process. Short-term storage results, when printing onto filter tape using inkjet printer $\# \mathrm{I}$ and then stored in folders, showed little difference (initial minus final: <1.4 ATN at either wavelength) across the three print densities tested (ATN ranging from $\sim 27$ to 70 at $880 \mathrm{~nm} ; 47$ to 98 at $370 \mathrm{~nm}$ ) with the largest relative difference at the lowest print density $(3.7 \%$ at $880 \mathrm{~nm})$. However, it is also important to evaluate the long-term stability for the purpose of using these samples as validation/reference materials for comparison of methods that measure optical attenuation and ensuring the samples are stored in the best possible manner. Samples printed onto filter tape with inkjet printer \#VI and stored in folders at room temperature for up to 5-7 months with no protection had differences (initial minus final) in ATN at $880 \mathrm{~nm}$ in the range from 1.0 to 5.9 ATN (average 2.7 ATN) with the largest difference in measured ATN at the darkest print density (133 ATN at $880 \mathrm{~nm}$ ). On a relative basis, the largest difference, up to $20 \%$, was observed at the lowest print density (ATN of 5.2, difference of $1 \mathrm{ATN}$ ) at $880 \mathrm{~nm}$. Examination of the inside of one or two folders, when using printer \#VI and at higher print densities, suggested that there was a possible loss of ink onto the inside of the folder, consistent with the observed positive difference (initial-final). This prompted the use of petri dishes to store filters. Samples printed with inkjet printer \#VI and stored in petri dishes for between 14 and 15 months at room temperature showed essentially no difference at either wavelength $(<2 \%)$ at all but the lowest print density, where a 3\% (0.2 ATN) and 17\% (1.1 ATN) difference was observed at $880 \mathrm{~nm}$ and $370 \mathrm{~nm}$, respectively.

\subsection{Chemical Analysis of the Inkjet Printer \#VI Ink}

The data sheet for the ink used in inkjet printer \#VI indicates that it is a pigmentbased black ink composed of proprietary organic material (e.g., oxygenated water-soluble solvents) (15-20\%); glycerols (5-10\%); carbon black (5-10\%); triethylene glycol monobutyl ether (TEGBE, $1-5 \%)$; and water $(65-70 \%)$, where the percentages are shown by weight. Carbon black is frequently the preferred pigment for black ink $[47,53,54,70]$.

The ink was analyzed for its EC and OC content by TOA [69] to determine the percentages of carbon black and organic carbon, respectively. We did not assume a conversion from carbon measured by TOA to organic material since the water-soluble organics in the pigment ink are proprietary. Based on potential compounds listed in [47], agreement to within a factor of two might be reasonable. Additionally, the ink was analyzed by sector-field-inductively coupled plasma mass spectrometer (SF-ICPMS) after microwave digestion for trace elements. Footnotes to Table S7 provide additional details regarding the chemical analysis of the ink. Standard quality assurance/quality control procedures were followed by the analysis laboratory (Wisconsin State Laboratory of Hygiene, Madison, WI, 
USA) for both carbon and trace element analysis. Aliquots of ink were weighed prior to either set of analyses.

The carbon black as measured by TOA comprises $3.4 \%$ by weight of the ink used in this method, whereas the specifications for the ink indicate a carbon black content of between 5 and $10 \%$ by weight. The difference between the manufacturer's specifications of the carbon black content of the ink versus our estimate is likely based on a direct gravimetric measurement of carbon black powder by the manufacturer that includes other components (organic species, trace element compounds, water) vs. our measurement as EC by TOA. While we realize that carbon black, BC, and EC are not the same [71], for purpose of methods comparisons, carbon black is a suitable alternative, especially given to the simplicity of the method proposed. Organic carbon comprises $15.3 \%$ by weight of the ink used in this method. A comparison of the organic fraction in the ink based on the data sheet to the OC measured by TOA could not be made since the organic compounds used in the ink are proprietary.

Fifty-one elements were measured by SF-ICPMS and comprised just over $0.127 \%$ of the mass of the sample analyzed. Potassium was the most abundant element in the ink ( 0.117 $\pm 0.010 \%$ by weight) followed by $\mathrm{Ca}$ and $\mathrm{Na}$. The ten highest concentration (ng/mL) elements are listed Table S7 Potassium (as $\mathrm{KOH}$ ), $\mathrm{Na}$ (as $\mathrm{NaOH}$ ), and $\mathrm{Li}$ (as $\mathrm{LiOH}$ ) are used in some pigmented inks as $\mathrm{pH}$ adjusting agents to neutralize acidic organic polymers used in formulating the ink (e.g., [72,73]; additionally, the inks exhibit greatly extended latency [73] when some or all of these elements are present. Trace element analysis was conducted primarily since some elemental oxides can impact the split of the OC/EC method as noted earlier. The low concentration of those elements is likely to have very little impact on the OC/EC split.

\section{Conclusions}

A simple and reproducible method has been developed and evaluated that provides validation/reference materials for the comparison of filter-based measurement methods of optical attenuation at $880 \mathrm{~nm}$ and $370 \mathrm{~nm}$ as well as for methods that measure of EC, OC, and TC content by thermal and thermal-optical analysis methods. Laser jet printers failed to meet our requirements for reproducibility, but we identified an inkjet printer that provided excellent results when depositing its ink onto different materials at various user defined print densities. Samples were simply taped to paper and passed through the printer in the normal manner and ATN was measured on each filter in triplicate before and after printing.

An extensive set of experiments was conducted to validate the method for optical attenuation at $880 \mathrm{~nm}$ and $370 \mathrm{~nm}$. Printing with the chosen printer was applied to a range of different substrates that included Teflon-coated glass-fiber filter material as used in the Aethalometer; quartz-fiber filters (QFF); and Teflon including "ringed Teflon", "Zefluor", and "TF-1000". The flexibility of the method was further tested by printing onto polypropylene and cellulose disks. The variability as the COV for each Aethalometer tape roll and print level (G173-G40, see Table 1) was less than $5 \%$ at both $880 \mathrm{~nm}$ and $370 \mathrm{~nm}$. At the lowest print level (G223; $880 \mathrm{~nm}$ ATN 6), it was normally less than 15\%.

The carbonaceous content of the ink deposit was quantified on QFF material by TOA, yielding mass loadings ( $\mu \mathrm{g} / \mathrm{cm}^{2}$ of filter) for EC, OC, and TC. Mass loadings by print density (labeled as print level) were compared to the optical attenuation obtained on each QFF. Linear relationships $\left(n=87, \mathrm{R}^{2} \sim 0.96\right.$ at $880 \mathrm{~nm}$ and $\sim 0.92$ at $\left.370 \mathrm{~nm}\right)$ were observed between optical attenuation on QFF and the amount of EC or OC measured by TOA. Slopes and intercepts for ATN as measured on QFF ( $x$-axis) and OC and EC ( $y$-axis) were similar and around $0.24-0.29$ and -4.2 and -4.0 ATN, respectively. Similar results were observed for TC.

The carbonaceous content of ink deposited on QFF also was compared to ATN measured on Aethalometer filter tape across the full range of print levels. Results were highly linear for EC and OC $\left(R^{2}>0.97\right.$ at either wavelength) for print levels up to G70. This 
may allow the mass of BC (measured at $880 \mathrm{~nm}$ ) and $\mathrm{BrC}$ (increment in ATN measured at $370 \mathrm{~nm}$ ) to be quantified, within the uncertainty of the method, on different substrates relative to the TOA method used here, including, for example, Aethalometer tape and Teflon filters.

A round robin employing four independent laboratories was conducted in comparison to the reference laboratory. Each laboratory volunteered their time to evaluate 3 sets of filters where each set consisted of roll filter material printed at seven print levels, a field blank, and laboratory blank (27 filters in total, each measured in triplicate). Extensive quality assurance was conducted to ensure the quality of results. The standard deviation at print level G70 (ATN 93 and 106 at $880 \mathrm{~nm}$ and $370 \mathrm{~nm}$, respectively) across the four participating groups and the reference laboratory was 1.3 ATN and 1.5 ATN, respectively, representing a COV of approximately $1.4 \%$ relative to the reference laboratory. These remarkably consistent results clearly indicate the viability of this simple as a reproducible method to produce validation/reference materials for the comparison of methods that measure optical attenuation at $880 \mathrm{~nm}$ and $370 \mathrm{~nm}$ for methods that estimate $\mathrm{BC}$ and $\mathrm{BrC}$ on filters. The consistency of the method to deposit ink on QFF also suggests that this method may be viable to create a validation/reference material for comparison of thermal and thermal-optical methods that measure OC and EC on QFF filters and total combustion methods that measure TC on QFF samples. This method may ultimately provide a means of relating the various filter-based optical attenuation methods, as a method to evaluate the split point and linearity of OC and EC by thermal and thermal-optical methods, and a possible calibration standard for TC by total combustion analysis.

Future efforts will include validating the methods at other wavelengths as used in various filter-based optical attenuation methods; and to independently quantify the amount of carbon black in the ink through chemical and gravimetric analysis, with the objective of providing a calibration standard for filter-based methods that measure BC, BrC, EC, OC, and TC.

Supplementary Materials: The following are available online at https: / www.mdpi.com/article / 10.3390/metrology1020010/s1: Figure S1: Comparison of optical attenuation measured at 6 print levels using different software programs-Adobe Photoshop (P) and Microsoft Word (W). Figure S2: Comparison of the thermal-optical analysis results using the software-chosen split time (variable) versus using a fixed split time of $480 \mathrm{~s}$ for (a) EC and (b) OC analysis. Figure S3: Comparison of optical attenuation measured at $370 \mathrm{~nm}$ on Aethalometer tape roll \#16 and OC mass loading $\left(\mu \mathrm{g} / \mathrm{cm}^{2}\right)$ measured on QFF ( $\mathrm{n}=11$ sets). Figure S4: Comparison of TC to ATN measured on QFF at $880 \mathrm{~nm}$ and $370 \mathrm{~nm}$ as a validation/reference material for comparison of filter-based methods that measure TC. Figure S5: Relationship between ATN at (a) $880 \mathrm{~nm}$ and (b) $370 \mathrm{~nm}$ on various substrates and print levels (arbitrary units based on the printer-software combination) using inkjet printer \#VI and Adobe Photoshop. Table S1: Variability of optical attenuation (ATN) measured at $880 \mathrm{~nm}$ and $370 \mathrm{~nm}$ through blank paper across multiple reams and boxes as indicated. Table S2: Variability of optical attenuation (ATN) measured at $880 \mathrm{~nm}$ and $370 \mathrm{~nm}$ through printed paper when laser jet toner, associated with different laser jet printers, at one print level was deposited onto the paper samples. Results are for multiple (n) sheets of printed paper and may be from sheets in multiple reams and boxes as indicated. Table S3: Variability of optical attenuation (ATN) measured at $880 \mathrm{~nm}$ and $370 \mathrm{~nm}$ through printed Aethalometer filter tape, when laser jet toner at one print level was deposited onto the filter tape samples using different laser jet printers. Table S4: Inkjet printer specifications. Table S5: Variability of optical attenuation (ATN) measured at $880 \mathrm{~nm}$ and $370 \mathrm{~nm}$ through printed Aethalometer filter tape using inkjet printers to deposit ink onto the filter tape samples at set print densities. Table S6: Results from round robin quality assurance at 7 print levels. Table S7: Chemical composition of ink used in inkjet printer \#VI.

Author Contributions: P.A.S. developed and oversaw all aspects of the project, was EPA's project officer and principal investigator prior to retiring from EPA in January 2019, directed and assisted with data analysis, and prepared this journal article. A.-M.H. conducted the experiments and data analysis and reviewed the journal article. A.D.A.H. provided insight into the project and assisted with preparation and review of the journal article. J.J.S., N.P.H., J.G.W., P.P.-J. and P.D. provided 
review of the journal article and contributed time and materials as participants in the round robin study. All authors have read and agreed to the published version of the manuscript.

Funding: This work was jointly funded by Magee Scientific Corporation, Berkeley, CA and the US EPA, Office of Research and Development, Las Vegas, NV and supported through Cooperative Research and Development Agreement (CRADA) between the US EPA and Magee Scientific (CRADA \#849-15 and amendment \#849-A-17). Ms. Hyatt, a contractor, was partially funded by Magee Scientific Corp. and through the US EPA by personal services contracts \#EP-16-W-000126 and EP16W000126.

Institutional Review Board Statement: Not applicable.

Informed Consent Statement: Not applicable.

Data Availability Statement: Not applicable.

Acknowledgments: The authors would like to thank UC Davis, Air Quality Research Center, Davis, CA; the Desert Research Institute, Division of Atmospheric Sciences, Reno, NV; RTI International, Research Triangle Park, NC; and the University of Wisconsin-Madison, Wisconsin State Laboratory of Hygiene, Madison, WI for their participation in the round robin study at no cost to the project. We also thank Martin Shafer, Alex Lai, and Robel Kebede of the University of Wisconsin-Madison, Madison, WI for their assistance with performing chemical analysis on printed QFF filters and ink. The following University of Nevada, Las Vegas, NV students participated in this study as student interns: Rebecca Ely, Shalini Dalpatadu, Elise Nguyen, Shandra D. Staker, and Kirk Ferguson. We thank them for their assistance with the project.

Conflicts of Interest: The authors declare no conflict of interest.

\section{References}

1. Bond, T.C.; Sun, H. Can reducing black carbon emissions counteract global warming? Environ. Sci. Technol. 2005, 39, 5921-5926. [CrossRef]

2. Bond, T.C.; Bergstrom, R.W. Light absorption by carbonaceous particles: An investigative review. Aerosol Sci. Technol. 2006, 40, 27-67. [CrossRef]

3. Bond, T.C.; Zarzycki, C.; Flanner, M.G.; Koch, D.M. Quantifying immediate radiative forcing by black carbon and organic matter with the specific forcing pulse. Atmos. Chem. Phys. 2011, 11, 1505-1525. [CrossRef]

4. Bond, T.C.; Doherty, S.J.; Fahey, D.W.; Forster, P.M.; Berntsen, T.; DeAngelo, B.J.; Flanner, M.G.; Ghan, S.; Kärcher, B.; Koch, D.; et al. Bounding the role of black carbon in the climate system: A scientific assessment. J. Geophys. Res. Atmos. 2013, 118, $5380-5552$. [CrossRef]

5. Chung, S.H.; Seinfeld, J.H. Climate response of direct radiative forcing of anthropogenic black carbon. J. Geophys. Res. 2005, 110, 1-25. [CrossRef]

6. EPA. Report to Congress on Black Carbon; External Peer Review Draft. U.S. Environmental Protection Agency Office of Air Quality Planning and Standards Research Triangle Park, North Carolina. 2011. Available online: https: //yosemite.epa.gov/sab/sabproduct.nsf/fedrgstr_activites/05011472499C2FB28525774A0074DADE/\$File/BC+RTC+ External+Peer+Review+Draft-opt.pdf (accessed on 6 November 2021).

7. ICPP. Technical Summary. In Climate Change 2007: The Physical Science Basis. Contribution of Working Group I to the Fourth Assessment Report of the Intergovernmental Panel on Climate Change; Solomon, S., Qin, D., Manning, M., Alley, R.B., Berntsen, T., Bindoff, N.L., Chen, Z., Chidthaisong, A., Gregory, J.M., Hegerl, G.C., et al., Eds.; Cambridge University Press: Cambridge, UK; New York, NY, USA, 2007; Available online: https:/ / www.ipcc.ch/report/ar4/wg1/ (accessed on 6 November 2021).

8. IPCC. Climate Change 2013. In The Physical Science Basis. Contribution of Working Group I to the Fifth Assessment Report of the Intergovernmental Panel on Climate Change; Stocker, F.T., Qin, D., Plattner, G.-K., Tignor, M., Allen, S.K., Boschung, J., Nauels, A., Xia, Y., Bex, V., Midgley, P.M., Eds.; Cambridge University Press: Cambridge, UK; New York, NY, USA, 2013; p. 1535. Available online: https:/ / www.ipcc.ch/report/ar5/wg1/ (accessed on 6 November 2021).

9. Ramanathan, V.; Carmichael, G. Global and regional climate changes due to black carbon. Nat. Geosci. 2008, 1, 221-227. Available online: https:/ / www.nature.com/articles/ngeo156 (accessed on 6 November 2021). [CrossRef]

10. Solomon, P.A.; Gehr, P.; Bennett, D.; Phalen, R.; Loyda, B.; Rothen-Rutishauser, B.M.; Clift, M.; Brandenberger, C.; Mühlfeld, C. Macroscopic to microscopic scales of particle dosimetry: From source to fate in the body. Air Qual. Atmos. Health 2012, 5, 169-187. Available online: https:/ /link.springer.com/content/pdf/10.1007\%2Fs11869-011-0167-y.pdf (accessed on 6 November 2021). [CrossRef]

11. Janssen, N.; Girlofs-Nijland, M.; Lanki, T.; Salonen, R.; Cassee, F.; Hoek, G.; Fischer, P.; Brunekreef, B.; Krzyzanowski, M. Health Effects of Black Carbon. The WHO European Centre for Environment and Health, Bonn; WHO Regional Office for Europe: Copenhagen, Denmark, 2012; Available online: https:/ /stg-wedocs.unep.org/bitstream/handle/20.500.11822/8699/Health_effects_black_ carbon.pdf?sequence=3\&isAllowed=y (accessed on 6 November 2021). 
12. Li, Y.; Henze, D.K.; Jack, D.; Henderson, B.H.; Kinney, P.L. Assessing public health burden associated with exposure to ambient black carbon in the United States. Sci. Total Environ. 2016, 539, 515-525. Available online: https://www.ncbi.nlm.nih.gov/pmc/ articles/PMC4761114/ (accessed on 6 November 2021). [CrossRef] [PubMed]

13. Luben, T.J.; Nichols, J.L.; Dutton, S.J.; Kirrane, E.; Owens, E.O.; Datko-Williams, L.; Madden, M.; Sacks, J.D. A systematic review of cardiovascular emergency department visits, hospital admissions and mortality associated with ambient black carbon. Environ. Int. 2017, 107, 154-162. Available online: https:/ / www.ncbi.nlm.nih.gov/pmc/articles/PMC6193259/ (accessed on 6 November 2021). [CrossRef]

14. Kirrane, E.F.; Luben, T.J.; Benson, A.; Owens, E.O.; Sacks, J.D.; Dutton, S.J.; Madden, M.; Nichols, J.L. A systematic review of cardiovascular responses associated with ambient black carbon and fine particulate matter. Environ. Int. 2019, 127, 305-316. [CrossRef]

15. Redaelli, M.; Sanchez, M.; Fuertes, E.; Blanchard, M.; Mullot, J.; Baeza-Squiban, A.; Garçon, G.; Léger, C.; Jacquemin, B. Health effects of ambient black carbon and ultrafine particles: Review and integration of the epidemiological evidence. Environ. Epidemiol. 2019, 3, 347-348. Available online: https:/ /journals.lww.com/environepidem/fulltext/2019/10001/health_effects_of_ambient_ black_carbon_and.1061.aspx (accessed on 6 November 2021).

16. Cassee, F.R.; Héroux, M.-E.; Gerlofs-Nijland, M.; Kelly, F. Particulate matter beyond mass: Recent health evidence on the role of fractions, chemical constituents and sources of emission. Inhal. Toxicol. 2013, 25, 802-812. [CrossRef]

17. Baumgardner, D.; Popovicheva, O.; Allan, J.; Bernardoni, V.; Cao, J.; Cavalli, F.; Cozic, J.; Diapouli, E.; Eleftheriadis, K.; Genberg, P.J.; et al. Soot reference materials for instrument calibration and intercomparisons: A workshop summary with recommendations. Atmos. Meas. Tech. 2012, 5, 1869-1887. [CrossRef]

18. Müller, T.; Henzing, J.S.; de Leeuw, G.; Wiedensohler, A.; Alastuey, A.; Angelov, H.; Bizjak, M.; Coen, M.C.; Engström, J.E.; Gruening, C.; et al. Characterization and intercomparison of aerosol absorption photometers: Result of two intercomparison workshops. Atmos. Meas. Tech. 2011, 4, 245-268. Available online: https://amt.copernicus.org/articles/4/245/2011/amt-4-2452011.pdf (accessed on 6 November 2021). [CrossRef]

19. Bond, T.C.; Anderson, T.L.; Campbell, D. Calibration and intercomparison of filter-based measurements of visible light absorption by aerosols. Aerosol Sci. Technol. 1999, 30, 582-600. [CrossRef]

20. Kondo, Y.; Sahu, L.; Kuwata, M.; Miyazaki, Y.; Takegawa, N.; Moteki, N.; Imaru, J.; Han, S.; Nakayama, T.; Oanh, K.N.T.; et al. Stabilization of the filter-based absorption photometry by the use of a heated inlet. Aerosol Sci. Technol. 2009, 43, 741-756. [CrossRef]

21. Lack, D.A.; Lovejoy, E.; Baynard, T.; Pettersson, A.; Ravishankara, A.R. Aerosol absorption measurement using photoacoustic spectroscopy: Sensitivity, calibration, and uncertainty developments. Aerosol Sci. Technol. 2006, 40, 697-708. [CrossRef]

22. Nakayama, T.; Kondo, Y.; Moteki, N.; Sahu, L.K.; Kinase, T.; Kita, K.; Matsumi, Y. Size-dependent correction factors for absorption measurements using filter-based photometers: PSAP and COSMOS. J. Aerosol Sci. 2010, 41, 333-343. [CrossRef]

23. Kirchstetter, T.W.; Novakov, T. Controlled generation of black carbon particles from a diffusion flame and applications in evaluating black carbon measurement methods. Atmos. Environ. 2007, 41, 1874-1888. [CrossRef]

24. Slowik, J.G.; Cross, E.S.; Han, J.-H.; Davidovits, P.; Onasch, T.B.; Jayne, J.T.; Williams, L.R.; Canagaratna, M.R.; Worsnop, D.R.; Chakrabarty, R.K.; et al. An inter-comparison of instruments measuring black carbon content of soot particles. Aerosol Sci. Technol. 2007, 41, 295-314. [CrossRef]

25. Chai, M.; Birch, M.E.; Deye, G. Organic and elemental carbon filter sets: Preparation method and interlaboratory results. Ann. Occup. Hyg. 2012, 56, 959-967. Available online: https://www.ncbi.nlm.nih.gov/pmc/articles/PMC3577040/ (accessed on 6 November 2021). [PubMed]

26. Currie, L.A.; Benner, B.A., Jr.; Kessler, J.D.; Klinedinst, D.B.; Klouda, G.A.; Marolf, J.V.; Slater, J.F.; Wise, S.A.; Cachier, H.; Cary, R.; et al. A critical evaluation of interlaboratory data on total, elemental, and isotopic carbon in the carbonaceous particle reference material, NIST SRM 1649a. J. Res. Natl. Inst. Stand. Technol. 2002, 107, 279-298. [CrossRef] [PubMed]

27. Lee, H.M.; Okuyama, K.; Mizohata, A.; Kim, T.O.; Koyama, H. Fabrication of reference filter for measurements of EC (elemental carbon) and OC (organic carbon) in aerosol particles. Aerosol Sci. Technol. 2007, 41, 284-294. [CrossRef]

28. Bae, M.-S.; Schauer, J.J.; Turner, J.R.; Hopke, P.K. Seasonal variations of elemental carbon in urban aerosols as measured by two common thermal-optical carbon methods. Sci. Total Environ. 2009, 407, 5176-5183. [CrossRef]

29. Chow, J.C.; Watson, J.G.; Crow, D.; Lowenthal, D.H.; Merrifield, T. Comparison of IMPROVE and NIOSH carbon measurements. Aerosol Sci. Technol. 2001, 34, 23-34. Available online: https://www.tandfonline.com/doi/abs/10.1080/02786820119073 (accessed on 6 November 2021). [CrossRef]

30. Chow, J.C.; Watson, J.G.; Chen, L.-W.A.; Arnott, W.P.; Moosmuller, H.; Fung, K.K. Equivalence of elemental carbon by Thermal/Optical Reflectance and Transmittance with different temperature protocols. Environ. Sci. Technol. 2004, 38, 4414-4422. [CrossRef]

31. ten Brink, H.; Maenhaut, W.; Hitzenberger, R.; Gnauk, T.; Spindler, G.; Even, A.; Chi, X.; Bauer, H.; Puxbaum, H.; Putaud, J.-P.; et al. INTERCOMP2000: The comparability of methods in use in Europe for measuring the carbon content of aerosol. Atmos. Environ. 2004, 38, 6459-6466. [CrossRef]

32. Watson, J.G.; Chow, J.C.; Chen, L.-W.A. Summary of organic and elemental carbon/black carbon analysis methods and intercomparisons. Aerosol Air Qual. Res. 2005, 5, 65-102. Available online: https:/ /aaqr.org/articles/aaqr-05-06-oa-0006.pdf (accessed on 6 November 2021). [CrossRef] 
33. Cheng, Y.; Zheng, M.; He, K.; Chen, Y.; Yan, B.; Russell, A.G.; Shi, W.; Jiao, Z.; Sheng, G.; Fu, J.; et al. Comparison of two thermal-optical methods for the determination of organic carbon and elemental carbon: Results from the south-eastern United States. Atmos. Environ. 2011, 45, 1913-1918. [CrossRef]

34. Giannoni, M.; Calzolai, G.; Chiari, M.; Cincinelli, A.; Lucarelli, F.; Martellini, T.; Nava, S. A comparison between thermal-optical transmittance elemental carbon measured by different protocols in PM2.5 samples. Sci. Total Environ. 2016, 571, $195-205$. [CrossRef]

35. Gundel, L.A.; Dod, R.L.; Rosen, H.; Novakov, T. The relationship between optical attenuation and black carbon concentration for ambient and source particles. Sci. Total Environ. 1983, 36, 197-202. [CrossRef]

36. Snyder, D.C.; Schauer, J.J. An inter-comparison of two black carbon aerosol instruments and a semi-continuous elemental carbon instrument in the urban environment. Aerosol Sci. Technol. 2007, 41, 463-474. [CrossRef]

37. Solomon, P.A.; Hansen, A.D.A.; Hyatt, A.-M. Reproducible Reference Standards for Filter-Based Measurements of Carbonaceous Aerosols Found in Environmental Samples. United States Patent Application, Pub. No. US 2019/0113431 A1, 18 April 2019. Assigned to the United States Government, Washington, DC. Available online: https:/ patentimages.storage.googleapis.com/35 /88/3f/25c12bad60d383/US20190113431A1.pdf (accessed on 6 November 2021).

38. Solomon., P.A.; Hopke, P.K.; Froines, J.; Scheffe, R. Key scientific and policy- and health-relevant findings from EPA's Particulate Matter Supersites Program and related studies: An integration and synthesis of results. J. Air Waste Manag. Assoc. 2008, 58, S1-S92. Available online: https: / www.proquest.com/docview / 214375417?pq-origsite=gscholar\&fromopenview=true (accessed on 6 November 2021). [CrossRef] [PubMed]

39. Solomon, P.A.; Lantz, J.J.; Crumpler, D.; Flanagan, J.B.; Jayanty, R.K.M.; Rickman, E.E.; McDade, C.; Ashbaugh, L. United States national PM2.5 chemical speciation monitoring Networks-CSN and IMPROVE: Description of networks. J. Air Waste Manag. Assoc. 2014, 64, 1410-1438. [CrossRef] [PubMed]

40. Kirchstetter, T.W.; Novakov, T.; Hobbs, P.V. Evidence that the spectral dependence of light absorption by aerosols is affected by organic carbon. J. Geophys. Res. Atmos. 2004, 109. [CrossRef]

41. Andreae, M.O.; Gelencsér, A. Black carbon or brown carbon? The nature of light-absorbing carbonaceous aerosols. Atmos. Chem. Phys. 2006, 6, 3131-3148. [CrossRef]

42. Sreekanth, V.; Tonne, C.; Salmon, M.; Arulselvan, S.; Marshal, D.J. The role of blank filter mass in attenuation measurements using an off-line transmissometer. J. Aerosol Sci. 2019, 131, 41-47. [CrossRef]

43. Johnson, M.M. Evaluation of a Multiwavelength Characterization of Brown and Black Carbon from Filter Samples. Master's Thesis, University of Nevada, Reno, NV, USA, 2015. Available online: https:/ / scholarworks.unr.edu/bitstream/handle/11714/ 2666/Johnson_unr_0139M_11943.pdf?sequence=1 (accessed on 6 November 2021).

44. Panteliadis, P.; Hafkenscheid, T.; Cary, B.; Diapouli, E.; Fischer, A.; Favez, O.; Quincey, P.; Viana, M.; Hitzenberger, R.; Vecchi, R.; et al. ECOC comparison exercise with identical thermal protocols after temperature offset correction-Instrument diagnostics by in-depth evaluation of operational parameters. Atmos. Meas. Tech. 2015, 8, 779-792. Available online: https:/ / amt.copernicus.org/articles/8/779/2015/amt-8-779-2015.pdf (accessed on 6 November 2021). [CrossRef]

45. Dutkiewicz, V.A.; DeJulio, A.M.; Ahmed, T.; Laing, J.; Hopke, P.K.; Skeie, R.B.; Viisanen, Y.; Paatero, J.; Husain, L. Forty-seven years of weekly atmospheric black carbon measurements in the Finnish Arctic: Decrease in black carbon with declining emissions. J. Geophys. Res. Atmos. 2014, 119, 7667-7683. [CrossRef]

46. Chow, C.; Watson, J.G.; Green, M.C.; Wang, X.; Chen, L.-W.A.; Trimble, D.L.; Cropper, P.M.; Kohl, S.D.; Gronstal, S.B. Separation of brown carbon from black carbon for IMPROVE and Chemical Speciation Network PM2.5 samples. J. Air Waste Manag. Assoc. 2018, 68, 494-510. [CrossRef]

47. Matsushita, Y. Ink Composition. United States Patent Application, Pub. No. US 2012/0236068 A1, 20 September 2012. Assigned to Fujifilm Corporation, Tokyo. Available online: https://patentimages.storage.googleapis.com/bb/f1/2f/bfffdf65023529/US201 20236068A1.pdf (accessed on 6 November 2021).

48. Bello, D.; Martin, J.; Santeufemio, C.; Sun, Q.; Bunker, K.L.; Shafer, M.; Demokritou, P. Physicochemical and morphological characterisation of nanoparticles from photocopiers: Implications for environmental health. Nanotoxicology 2013, 7, 989-1003. [CrossRef]

49. Pirela, S.V.; Sotiriou, G.A.; Bello, D.; Shafer, M.; Bunker, K.L.; Castranova, V.; Thomas, T.; Demokritou, P. Consumer exposures to laser printer-emitted engineered nanoparticles: A case study of life-cycle implications from nano-enabled products. Nanotoxicology 2015, 9, 760-768. [CrossRef]

50. Shara, S.I.; Moustafay, Y.M.; Bakr, A.A.; Aboul El Magd, A.A.; Abd El-Aziz, I.M. Application of some physical techniques for forensic discrimination of printer toner. Egypt J. Chem. 2018, 61, 131-142. Available online: https://ejchem.journals.ekb.eg/ article_4495.html (accessed on 6 November 2021). [CrossRef]

51. Chow, J.C.; Watson, J.G.; Chen, L.-W.A.; Paredes-Miranda, G.; Chang, M.-C.O.; Trimble, D.; Fung, K.; Zhang, H.; Yu, J.Z. Refining temperature measures in thermal/optical carbon analysis. Atmos. Chem. Phys. 2005, 5, 4477-4505. [CrossRef]

52. Wang, Y.; Chung, A.; Paulson, S.E. The effect of metal salts on quantification of elemental and organic carbon in diesel exhaust particles using thermal-optical evolved gas analysis. Atmos. Chem. Phys. 2010, 10, 11447-11457. Available online: https: / / acp.copernicus.org/articles/10/11447/2010/acp-10-11447-2010.pdf (accessed on 6 November 2021). [CrossRef] 
53. Bauer, S.W.; Zeying, M. Pigment-based Inks for Ink-jet Printing. European Patent Specification, Pub. No. EP1589081B1, 13 August 2013. Assigned to Hewlett-Packard Development Company, L.P. San Diego, CA. Available online: https: / / patentimages.storage.googleapis.com/e6/cc/e7/a2c529f5e1b1de/EP1589081B1.pdf (accessed on 6 November 2021).

54. Katsen, B.J.R.; Himmelwright, S.; Schwartz, N.R.; Stewart, B.J. Black Ink Jet Ink Composition. United States Patent, US5803958A, 8 September 1998. Assigned to Rexam Graphics, Inc. South Hadley, MA. Available online: https://patentimages.storage. googleapis.com/24/4c/8a/45d6fbf12e07d8/US5803958.pdf (accessed on 6 November 2021).

55. Chow, C.; Watson, J.G.; Green, M.C.; Frank, N.H. Filter light attenuation as a surrogate for elemental carbon. J. Air Waste Manag. Assoc. 2010, 60, 1365-1375. [CrossRef] [PubMed]

56. White, H.W.; Krystyna, T.; Nicole, P.; Schichtel, H.; Schichtel, B.A. A critical review of filter transmittance measurements for aerosol light absorption, and de novo calibration for a decade of monitoring on PTFE membranes. Aerosol Sci. Technol. 2016, 50, 984-1002. [CrossRef]

57. Presler-Jur, P.; Doraiswamy, P.; Hammond, O.; Rice, J. An evaluation of mass absorption cross-section for optical carbon analysis on Teflon filter media. J. Air Waste Manag. Assoc. 2017, 67, 1213-1228. [CrossRef] [PubMed]

58. Dillner, A.M.; Takahama, S. Predicting ambient aerosol thermal-optical reflectance (TOR) measurements from infrared spectra: Organic carbon. Atmos. Meas. Tech. 2015, 8, 1097-1109. [CrossRef]

59. Dillner, A.M.; Takahama, S. Predicting ambient aerosol thermal-optical reflectance measurements from infrared spectra: Elemental carbon. Atmos. Meas. Tech. 2015, 8, 4013-4023. [CrossRef]

60. Weakley, W.T.; Takahama, S.; Dillner, A.M. Thermal/optical reflectance equivalent organic and elemental carbon determined from federal reference and equivalent method fine particulate matter samples using Fourier transform infrared spectrometry. Aerosol Sci. Technol. 2018, 52, 1048-1058. [CrossRef]

61. Sun, H.; Biedermann, L.; Bond, T.C. Color of brown carbon: A model for ultraviolet and visible light absorption by organic carbon aerosol. Geophys. Res. Lett. 2007, 34. [CrossRef]

62. Forrister, H.; Liu, J.; Scheuer, E.; Dibb, J.; Ziemba, L.; Thornhill, K.L.; Anderson, B.; Diskin, G.; Perring, A.E.; Schwarz, J.P.; et al. Evolution of brown carbon in wildfire plumes. Geophys. Res. Lett. 2015, 42, 4623-4640. [CrossRef]

63. Healy, R.M.; Wang, J.M.; Jeong, C.-H.; Lee, A.K.Y.; Willis, M.D.; Jaroudi, E.; Zimmerman, N.; Hilker, N.; Murphy, M.; Eckhardt, S.; et al. Light-absorbing properties of ambient black carbon and brown carbon from fossil fuel and biomass burning sources. J. Geophys. Res. Atmos. 2015, 120, 6619-6633. [CrossRef]

64. Washenfelder, R.A.; Attwood, A.R.; Brock, C.A.; Guo, H.; Xu, L.; Weber, R.J.; Ng, N.L.; Allen, H.M.; Ayres, B.R.; Baumann, K.; et al. Biomass burning dominates brown carbon absorption in the rural southeastern United States. Geophys. Res. Lett. 2015, 42, 653-664. [CrossRef]

65. EPA. Wildland Fire Research to Protect Health and the Environment. US EPA, Research Triangle Park, NC. 2019. Available online: https: / / www.epa.gov/air-research/wildland-fire-research-protect-health-and-environment (accessed on 6 November 2021).

66. Kitto, M.E.; Anderson, D.L. The use of Whatman-41 filters for particle collection. Atmos. Environ. 1988, 22, 2629-2630. [CrossRef]

67. Pekney, N.J.; Davidson, C.I. Determination of trace elements in ambient aerosol samples. Anal. Chim. Acta 2005, 540, 269-277. [CrossRef]

68. Upadhyay, N.; Majestic, B.J.; Prapaipong, P.; Herckes, P. Evaluation of polyurethane foam, polypropylene, quartz-fiber, and cellulose substrates for multi-element analysis of atmospheric particulate matter by ICP-MS. Anal. Bioanal. Chem. 2009, 394, 255-266. Available online: https:/ /link.springer.com/article/10.1007\%2Fs00216-009-2671-6 (accessed on 6 November 2021). [CrossRef]

69. Schauer, J.J.; Mader, B.T.; DeMinter, J.T.; Heidemann, G.; Bae, M.S.; Seinfeld, J.H.; Flagan, R.C.; Cary, R.A.; Smith, D.; Huebert, B.J.; et al. ACE-Asia intercomparison of a thermal-optical method for the determination of particle-phase organic and elemental carbon. Environ. Sci. Technol. 2003, 37, 993-1001. [CrossRef]

70. Ikoshi, M.; Tojo, K. Inkjet Recording Liquid. United States Patent Application, Pub. No. US 2010/0168322 A1, 1 July 2010. Assigned to Fujifilm Corporation, Falls Church, VA. Available online: https://patentimages.storage.googleapis.com/f4/b3/02/ 03208ca53a5932/US20100168322A1.pdf (accessed on 6 November 2021).

71. Long, C.M.; Nascarella, A.M.; Valberg, A.P. Carbon black vs. black carbon and other airborne materials containing elemental carbon: Physical and chemical distinctions. Environ. Pollut. 2013, 181, 271-286. [CrossRef]

72. Jackson, C. Inkjet Ink. International Patent Application. International Pub. No. WO 2008/130625 Al, Published 30 October 2008. Wilmington, DE. Available online: https:/ / patentimages.storage.googleapis.com/9b/78/d1/aa057f06352125/WO2008130625A1 .pdf (accessed on 6 November 2021).

73. Yau, H.-L.; Krzemien, W.; Flood, E. Preferred Materials for Publication Classification Pigmented Inkjet Ink. United States Patent Application, Pub. No. US 2004/0085418A1, 6 May 2004. Assigned to Eastman Kodak Company, Rochester, NY. Available online: https:/ / patentimages.storage.googleapis.com/86/23/50/c6de4cbf7d6055/US20040085418A1.pdf (accessed on 6 November 2021). 